\title{
Antibiotic resistance in bacteria
}

\author{
-a review based on a symposium held on 5 January 1991 at Addenbrookes Hospital, Cambridge and chaired by \\ Professor J. T. Smith
}

\author{
Edited by S. G. B. AMYES and C. G. GEMMELL*
}

Department of Medical Microbiology, The Medical School, University of Edinburgh, Teviot Place, Edinburgh EH8 $9 A G$ and "Department of Bacteriology. The Medical School, University of Glasgow, Royal Infirmary, 86 Cast/e Street, Glasgow, G4 OSF

\section{Introduction}

Antibiotic resistance tends to be discussed by groups who work on related antibiotics. The symposium, which provided the basis for this review, was a rare opportunity for scientists working on quite different aspects of resistance to present and discuss their results. Much emphasis has been placed on the mechanisms of resistance and the first five papers reflect this. They demonstrate the quite different resistance problems encountered with each class of antibacterial drug. The remaining four papers take a different, and often less expressed approach, examining the impact that resistance has on clinical populations and our ability to treat the patient. These papers examine the effect that resistance has on the virulence and pathogenicity of bacteria and how the host is affected by resistant strains. This section ends with views about the future of antibiotics.

RESISTANCE TO ANTIFOLIATE ANTIBACTERIAL AGENTS

\section{K. J. Towner}

Department of Microbiology and PHLS Laboratory, University Hospital, Nottingham NG7 $2 \mathrm{UH}$

The folate pathway occupies a central metabolic role leading to protein and nucleic acid synthesis (fig. 1). Two types of antifolate agent have gained wide acceptance and are of clinical importance: (i) the sulphonamides, that inhibit the bacterial enzyme dihydropteroate synthetase (DPS), which catalyses the reaction of $p$-aminobenzoic acid (PABA) with a pteridine derivative and are selectively toxic for bacteria because man does not require this enzyme; (ii) trimethoprim, that inhibits the ubiquitous enzyme dihydrofolate reductase (DHFR), and is selectively toxic because its affinity for the bacterial enzyme is some 10000 -fold greater than that for the mammalian enzyme. Following its initial introduction, trimethoprim was prescribed originally only in combination with a sulphonamide, usually sulphamethoxazole, for reasons which, at the time, seemed justified, but upon which, for many applications, substantial doubt was subsequently cast. ${ }^{1,2}$ In this paper, acquired resistance to sulphonamides and trimethoprim is summarised with particular reference to recent developments in molecular biology which enhance our understanding of resistance to these important antibiotics.

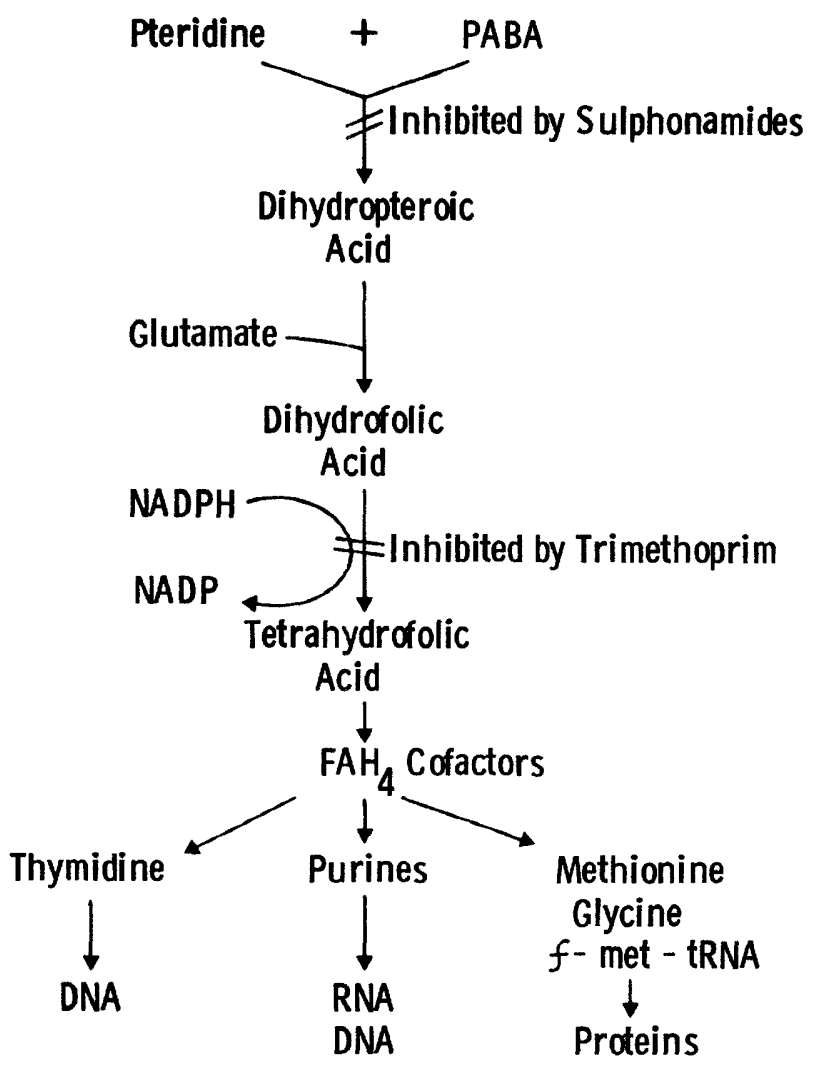

Fig. 1. Reactions involve in the folate pathway.

\section{Incidence of resistance}

Although a prime requirement is to distinguish between intrinsic and acquired resistance, other difficulties have been caused in the past by the use of different definitions for the term "resistant". In addition to the fact that clinically relevant resistance is not the same as laboratory-determined resistance, particular problems arise in susceptibility to sulphonamides and trimethoprim in relation to choice of resistance breakpoints, inoculum size and the correct medium. ${ }^{3}$ Other local factors, such as the occurrence of epidemic strains, or selection and choice of particular specimens and patients, may greatly influence the "incidence" of resistant strains. Therefore, assessments of changes 
Table I. Incidence of resistance to sulphonamides $(\mathrm{Su})$ or trimethoprim $(\mathrm{Tp})$, or both, among isolates of enterobacteria causing urinary tract infection from the Nottingham area

\begin{tabular}{|c|c|c|c|c|c|c|}
\hline \multirow{2}{*}{ Species } & & \multicolumn{3}{|c|}{ Percent of isolates that were } & \multicolumn{2}{|c|}{ Total per cent that were } \\
\hline & & $\mathrm{Su}^{\mathrm{R}} \mathrm{T} \mathrm{p}^{\mathrm{S}}$ & $\mathrm{Su}^{\mathrm{R}} \mathrm{Tp}^{\mathrm{R}}$ & $\mathrm{Su}^{\mathrm{S}} \mathrm{Tp}^{\mathrm{R}}$ & $\mathrm{Su}^{\mathrm{R}}$ & $T_{p} p^{R}$ \\
\hline \multirow[t]{2}{*}{ E. coli } & Hosp. & $20 \cdot 2$ & $14 \cdot 3$ & $5 \cdot 1$ & $34 \cdot 5$ & $19 \cdot 4$ \\
\hline & Comm. & $18 \cdot 3$ & $13 \cdot 3$ & $4 \cdot 3$ & $31 \cdot 6$ & $17 \cdot 6$ \\
\hline \multirow{2}{*}{$\begin{array}{l}\text { Klebsiella/Entero- } \\
\text { bacter spp. }\end{array}$} & Hosp. & $7 \cdot 6$ & $10 \cdot 2$ & $5 \cdot 7$ & $17 \cdot 8$ & 15.9 \\
\hline & Comm. & $9 \cdot 8$ & $11 \cdot 0$ & $8 \cdot 2$ & $20 \cdot 8$ & $19 \cdot 2$ \\
\hline \multirow[t]{2}{*}{ Proteus spp. } & Hosp. & $4 \cdot 0$ & $7 \cdot 7$ & $14 \cdot 3$ & $11 \cdot 7$ & $22 \cdot 0$ \\
\hline & Comm. & $3 \cdot 7$ & $6 \cdot 3$ & $15 \cdot 5$ & $10 \cdot 0$ & $21 \cdot 8$ \\
\hline
\end{tabular}

$R$, resistant; $S$, sensitive.

* Resistance was defined as described previously, ${ }^{7}$ with breakpoints of trimethoprim lactate $8 \mu \mathrm{g} / \mathrm{ml}$ and sulphamethoxazole $16 \mu \mathrm{g} / \mathrm{ml}$.

in resistance are more significant if they are made from longterm follow-up surveys in a single centre, and several such surveys have been performed with isolates of Enterobacteriaceae from different parts of the world. ${ }^{4}$

Table I summarises the latest available data (1989) on the incidence of resistance to sulphonamides and trimethoprim among isolates of Enterobacteriaceae causing urinary infection from the Nottingham area. The incidence of sulphonamide resistance has remained stable for many years, but the incidence of resistance to trimethoprim has increased considerably since surveillance commenced in 1978.5 With the exception of localised outbreaks of infection with resistant strains, comparable incidences of resistance in Enterobacteriaceae are also found generally in other developed countries. ${ }^{4}$ In contrast, the incidence of resistance to sulphonamides or trimethoprim, or both, in developing countries tends to be considerably higher $(30-60 \%$ in genera hospital isolates of Escherichia coli ). ${ }^{4,6}$ These higher incidences probably reflect the epidemic spread of particular resistant strains, plasmids or transposons in response to the continuous selection pressure imposed by the careless or unregulated use of trimethoprim and other antibiotics.

Table I also provides an interesting illustration of the effect of changes in selection pressure. Trimethoprim was, originally, prescribed always in combination with a sulphonamide. Consequently, all strains resistant to trimethoprim were also resistant to sulphonamides. Trimethoprim became available for use alone in the UK in 1979 and, since then, the proportion of strains resistant to trimethoprim and susceptible to sulphonamides has increased steadily ${ }^{7}$ to the levels shown in table I. In the light of earlier controversy, 1,2 it is interesting, although rather academic, to speculate as to whether the same overall incidence of trimethoprim resistance in Enterobacteriaceae would have been reached so rapidly had trimethoprim continued to be prescribed only in combination with a sulphonamide.

The situation in gram-positive bacteria is somewhat different. Although resistance to sulphonamides has been known for many years, the incidence of acquired trimethoprim resistance remained negligible until the advent of methicillin-resistant staphylococci (MRS) in the early 1980s. A considerable number of MRS are resistant also in trimethoprim, ${ }^{4}$ but the overall frequency of strains with resistance to both methicillin and trimethoprim varies widely among strains of different origin, depending largely on the occurrence of outbreaks of infection involving particular resistant strains, but is generally low. ${ }^{4}$

\section{Mechanisms of resistance to sulphonamides}

Resistance to sulphonamides may be encoded either by the chromosome or by plasmids. Chromosomal mutations leading to hyper-production of PABA occur and these overcome the metabolic block imposed by the inhibition of DPS by sulphonamides, but they seem to be of relatively minor clinical importance. The commonest mechanism of resistance is the production of an altered form of DPS for which sulphonamides have a reduced affinity. Although chromosomal mutations leading to the production of such altered enzymes may occur, most clinically significant sulphonamide resistance is associated with the production of altered forms of DPS encoded by antibiotic resistance plasmids.

Two distinct types of DPS (I and II) encoded by plasmids have been characterised in gram-negative bacteria; DPS-I (encoded by the gene sulI), has only $57 \%$ nucleotide sequence homology with DPS-II (encoded by sullI), and their deduced polypeptides show only c. $50 \%$ similarity. ${ }^{8}$ The sull gene is often located on transposons related to $\mathrm{Tn} 21$, or on large self-transmissible plasmids that show similarities to Tn21 in the resistance region..$^{9}$ In contrast, the sulII gene not only encodes a different enzyme, but is associated with different types of plasmids. The DPS-II enzyme is somewhat more stable in a cell-free extract than DPS-I, and the sulII gene is carried mainly on small non-conjugative plasmids. ${ }^{8,10}$ Both of these plasmid-encoded enzymes can be distinguished readily from the resistant DPS encoded by the sulA gene on the chromosome of Streptococcus pneumoniae, ${ }^{11}$ with $43 \%$ DNA similarly between sulA and sulI or sulII, respectively. ${ }^{8}$

\section{Mechanisms of resistance to trimethoprim}

Acquired resistance to trimethoprim may also be encoded by the chromosome or by antiobiotic resistance plasmids. There is in-vitro evidence that trimethoprim can select for chromosomal mutants of pathogenic bacteria that lack the enzyme thymidylate synthetase. ${ }^{11}$ Such "thy" mutants have lost the normal ability to synthesise thymidylate and, in order to grow, require exogenous supplies of thymine or thymidine to enable them to synthesise thymidylate via the "salvage" pathway. ${ }^{12}$ The action of trimethoprim would be adversely affected by the presence of such exogenous supplies under pathological conditions, but very few clinical isolates with this mechanism of resistance have been reported, ${ }^{3}$ perhaps because of failure to recognise them.

An alternative type of resistance is observed when mutations lead to overproduction of the normal chromosomally encoded DHFR. Mutants of this type have been obtained from several gram-positive and gram-negative species in vitro, ${ }^{3}$ but, again, seem to be relatively rare among clinical isolates. ${ }^{13}$ Impermeability mutants have also been reported in a various genera, and are of particular interest because of the reported cross-resistance between trimethoprim and other antibiotics such as the quinolones. ${ }^{14}$ 
However, as with the sulphonamides, the commonest mechanism of acquired resistance to trimethoprim results from the production of an insusceptible target enzyme. Mutant forms of the normal susceptible DHFR encoded by the chromosome have been found occasionally in clinical isolates, ${ }^{13}$ but by far the most important and commonest mechanism of resistance is associated with the production of an additional, insusceptible, form of DHFR encoded by genes located on self-transmissible or mobilisable plasmids and transposons. ${ }^{4}$ The remainder of this section is devoted to a brief description of these enzymes and the possible evolutionary relationships between them.

Plasmid-mediated trimethoprim resistance was dominated initially by the spread of genes encoding DHFR types I and II, but seven major groups (types I-VII) of DHFRs insusceptible to trimethoprim have now been characterised in gram-negative bacteria. Several of these major groups are further divided into subtypes, and an additional insusceptible DHFR (type S1) has been characterised in staphylococci. The identification of each of these enzyme types on the basis of biochemical and biophysical properties has been reviewed previously ${ }^{4}$ and, as with the plasmid-encoded $\beta$-lactamases, further DHFR types probably await discovery. Indeed, it should be noted that two DHFRs isolated independently in the UK and Scandinavia have both been designated "type VII" ${ }^{15,16}$ The remainder of this article refers to the UK enzyme, but further adjustments in nomenclature may be required when the precise relationship between these two enzymes, and the other DHFRs characterised previously, has been investigated fully.

The time-consuming nature of biochemical identification, involving the extraction and purification of each individual enzyme, has encouraged the development of a set of DNA probes which are capable of distinguishing between the genes encoding the different enzymes. These probes are particularly useful for epidemiological studies ${ }^{17}$ and are a vailable currently for DHFR groups I-V, VII and S1. ${ }^{4,18,19}$ When used in combination with high stringency wash conditions, the probe set is capable of distinguishing clearly between the major enzyme groups. One anomaly concerns DHFR group III, which had originally been thought to contain three directly related subtypes-IIIa, IIIb and IIIc. Each subtype has similar biochemical properties, albeit with markedly different iso-electric points, and confers only a moderate level of trimethoprim resistance. ${ }^{4}$ However, no hybridisation has been detected between the standard group III probe (constructed from the type IIIa gene) and the genes encoding types IIIb and IIIc (C. J. Thomson and S. G. B. Amyes, personal communication). Therefore, it seems probable that enzymes belonging to these subtypes, although similar biochemically, may have evolved independently (see below).

Further investigations of the possible evolutionary relationships between the different DHFR groups have been stimulated, in part, by observations that some of the groupspecific DHFR probes can, when used under conditions of reduced stringency, react with genes encoding enzymes belonging to other DHFR groups. ${ }^{4}$ Several of the enzymes and genes involved have now been sequenced, with particular attention being paid to the amino terminal ( $N$ terminal) region which forms most of the active site for all DHFRs.

The two subtypes within group I (Ia and Ib) share $71 \%$ amino acid homology and $65 \%$ nucleic acid homology with each other (H.-K. Young, personal communication), but only $29 \%$ amino-acid homology with the susceptible chromosomal DHFR ${ }^{4}$

The three subtypes within group II (IIa, IIb and IIc) share extensive $(>78 \%)$ amino-acid sequence homology with each other, ${ }^{4}$ but are quite unlike any other plasmid or chromosomal DHFR; it has been postulated that they may be derived from an oxidoreductase which acted originally on a completely different substrate.

The type IIIa DHFR shares $51 \%$ homology with the $E$. coli chromosomal enzyme, perhaps suggesting that they may have shared a common evolutionary origin. ${ }^{4}$ In contrast, the type IIIb enzyme is clearly distinct from the type IIIa enzyme, sharing only 15 of the first 47 amino acids in the Nterminal sequence, and differs also from the $E$. coli chromosomal enzyme and the types I, II, V and S1. ${ }^{20}$ These observations support the hypothesis, referred to above, that the subtypes IIIa and IIIb, although biochemically similar, have evolved independently.

The type IV enzyme, like subtype IIIa, shows most homology $(40 \%)$ with the $E$. coli chromosomal enzyme, but is clearly distinct from the other plasmid-encoded DHFRs. ${ }^{21}$

The type $V$ enzyme, in contrast, is closely related to the types $\mathrm{Ia}^{9}$ and $\mathrm{Ib}$ (H.-K. Young, personal communication), with $75 \%$ and $87 \%$ homology respectively. There is a similar close relationship between the type VI enzyme and types Ia $\left(63 \%\right.$ homology) and V (61\% homology). ${ }^{22}$ Sequencing results for the type VII enzyme are not available yet, but hybridisation experiments have indicated a close relationship between the the V and VII genes. ${ }^{19}$

All of the plasmid-encoded DHFRs from gram-negative bacteria seem to be unrelated to DHFR type S1 from grampositive bacteria. ${ }^{4}$

\section{Envoi}

Genes encoding resistance to the main antifolate antibacterial agents, sulphonamides and trimethoprim, are now distributed widely among bacteria in most environments. The precise incidence of resistance in local ecosystems is probably related closely to the extent of the selection pressure exerted by local usage of antibiotics. Most clinically significant resistance to antifolates is associated with plasmid-carried genes, often transposable, which encode alternative drug-insusceptible target enzymes. Two major types of plasmid-encoded DPS conferring resistance to sulphonamides have been characterised, and trimethoprim resistance is conferred by at least seven major groups of plasmid-encoded DHFR in gram-negative bacteria, with an additional plasmid-encoded DHFR in gram-positive bacteria. Among the gram-negative DHFRs, groups I, V, VI and VII seem to be closely related, groups IIIa and IV show some similarities to trimethoprim-susceptible chromosomally-encoded enzymes, and group II enzymes seem to be completely distinct from all other types. The combined use of biochemical and molecular biological techniques has enabled the inter-relationships between the different genes and enzymes to be investigated, and is now providing us with an insight into the evolutionary mechanisms underlying the emergence of resistance to the antifolate antibacterials, and perhaps to antibiotics in general.

\section{Plasmid-MEDIATED $\beta$-LACTAMASES RESPONSIBLE} FOR PENICILLIN AND CEPHALOSPORIN RESISTANCE

\section{S. G. B. Amyes, D. J. Payne* and S. K. du Bois}

Department of Medical Microbiology, The Medical School, University of Edinburgh. *Present address: SmithKline Beechams Pharmaceuticals, Brockham Park, Betchworth, Surrey RH $37 A J$

Alexander Fleming's major contribution to medical science was the recognition of the potential of pencillin. He could not have known that he had stumbled upon a group of antibiotics that were not only going to prove to be the most extensively used antibacterial agents throughout the world but also prove to be the most durable. As with almost every other group of antibacterial drugs, the emergence of bacterial 
resistance soon threatened their future value. The 50th anniversary of Abraham and Chain's first discovery of an enzyme capable of destroying penicillin, ${ }^{23}$ a $\beta$-lactamase, has just passed and there is still much debate as to whether $\beta$-lactamases really do compromise our reliance on this group of drugs.

If we had had only pencillin $G$, this battle may have been lost. The strategy used to overcome $\beta$-lactamase attack was to modify the antibiotic so that it was no longer capable of fitting into the active site of the enzyme. This proved successful for a period with the $\beta$-lactamases produced by staphylococci. The ability to prepare 6-amino penicillanic acid and substitute functional groups, which do not allow the binding of the antibiotic at the active site of the enzyme, to produce methicillin and the oxacillins, kept the staphylococci under control for more than 10 years. However, the adaptability of the $\beta$-lactamases and the acquisition of a gene capable of changing the penicillin binding protein (PBP) 2, has now put many staphylococci beyond the reach of $\beta$-lactams. Neu demonstrated that, in the developed world, more than $95 \%$ of nosocomial staphylococci possessed $\beta$-lactamases. ${ }^{24}$

The stubstitution of functional groups on 6-amino penicillanic acid led to the development of ampicillin, amoxycillin and carbenicillin and allowed the large Gram-negative rods to be controlled by penicillins. The widespread use of ampicillin resulted in the emergence of resistance in 1962. Anderson and Datta ${ }^{25}$ showed that resistance to ampicillin could be plasmid-mediated and thus became freely transferable from one species to another. However, little distinction was made between plasmid and chromosomally-determined $\beta$-lactamases. In 1973, Richmond and Sykes divided all $\beta$ lactamases into five groups based on the substrate profile and response to inhibitors. ${ }^{26}$ The substrate profiles were, at best, $V_{\max }$ determinations and often were merely determinations of rates of hydrolysis at a single fixed substrate concentration. This value was usually expressed relative to that obtained with a standard $\beta$-lactam substrate, i.e., penicillin $G$, ampicillin, or cephaloridine. The rate of hydrolysis allowed a preliminary classification into oxacillinases, carbenicillinases or broad-spectrum drugs. However, this method of classification had a number of drawbacks. It did not take account of the affinity of the $\beta$-lactamase for the substrate (i.e., the $\vec{K}_{m}$ ) nor did it consider amino-acid sequence homology. It classified all plasmid encoded $\beta$ lactamases into just two of the groups, based on the inhibitory activity of cloxacillin.

Ambler ${ }^{27}$ introduced a scheme based on sequence homology of the amino acids. He identified two classes of enzymeClass A enzymes have a serine group at their active site and have a mol. wt of $c .29000$. They are either penicillinases or broad spectrum. These enzymes show considerable homology with $D$-alanine carboxypeptidase and may have a common evolutionary origin. Both chromosomal and plasmid-determined enzymes fall into the group. Class B enzymes include metallo-enzymes and have no amino acid homology with Class A enzymes. Class $C$ was added by Jaurin and Grundstrom, ${ }^{28}$ to include $\beta$-lactamases with serine involved in the active site but very different in structure from Class A proteins. These enzymes determine cephalosporin resistance, showing no sequence homology with Class A enzymes. Huovinen et al., having sequenced the enzyme PSE- $2^{29}$ and compared its structure with the OXA-2 $\beta$-lactamase, ${ }^{30}$ proposed a fourth class $D$; enzymes of quite distinct substrate specificities had related structures. The final class, E, was created for the $\beta$-lactamases from Xanthomonas maltophilia, metallo-enzymes like Class B but with no sequence homology with Class B. ${ }^{31}$ This scheme again classified all plasmidencoded $\beta$-lactamases into two groups, which were still very broad. Indeed, some of these enzymes within a class show less than $40 \%$ homology with other $\beta$-lactamases.
Huletsky et al. $^{32}$ recently reported the phylogenetic relationships between the Class $A \quad \beta$-lactamases that have been sequenced. His cladogram showed a vast diversity in amino acid structure, with as little as $35 \%$ homology, although the basic shape of the molecule is conserved. Whereas this scheme may indicate how related enzymes may be, it cannot be extended to allow comparison of $\beta$ lactamases in the clinical situation. This is demonstrated with three enzymes in this group, TEM-1, TEM-3 and SHV 1. TEM-1 and SHV-1 are very similar biochemically; they hydrolyse penicillins and early cephalosporins, but not later cephalosporins. However, they are phylogenetically so far apart that a gene probe for one will not hybridise with the other as there is only $65 \%$ homology. On the other hand, TEM-1 and TEM-3 have $99 \%$ sequence homology, ${ }^{33}$ but TEM-3 has the distinction that it can hydrolyse, and confer resistance to, ceftazidime and cefotaxime. This difference has immense clinical significance. Gene probing with a TEM-1 gene probe cannot distinguish it from the TEM-1 gene.

In the clinical environment, change in enzyme structure is a relatively slow occurrence and happens in small stages. Therefore, a scheme distinguishing enzymes or genes must be very sensitive. This problem was ameliorated by the development of iso-electric focusing by Matthew and colleagues. ${ }^{34}$ This technique, relying on the characteristic iso-electric point (pI) of enzymes, can, at its highest degree of sophistication, detect single amino acid differences in certain parts of the molecule. An equally sensitive technique, still much in its infancy, is the use of oligonucleotides designed to identify one nucleotide change. However, its success relies on the correct choice of probes. Iso-electric focusing has been the technique universally used and it has been combined with substrate profiles for finer distinction. At first, these compared relative rates at fixed substrate concentrations but, more recently compared relative $\mathrm{V}_{\max }$ values or relative rates of efficiency $\left(\mathrm{V}_{\max } / \mathrm{K}_{\mathrm{m}}\right)$.

Several surveys performed in Europe during the 1980s, employing these techniques, ${ }^{35-37}$ demonstrated that the TEM-1 $\beta$-lactamase was by far the most prevalent plasmidencoded enzyme, responsible for up to $80 \%$ of the ampicillin resistance mediated by plasmids in gram-negative rods. The next most prevalent enzyme was TEM-2, which varies by one amino acid change from glutamine to lysine at position 37 (on the Sutcliffe numbering scheme). This change produces no apparent alteration in biochemical properties or resistance phenotype. Thus, we can assume that, as far as $\beta$-lactam substrates are concerned, these enzymes are identical, and that their relative distributions of about $8: 1$ come from the relative success of the transposons on which the genes are carried. An equally prevalent enzyme, SHV-1, though phylogenetically distinct, again has very similar properties. The proportion of gram-negative bacteria resistant to ampicillin can vary in the developed world but is usually quite high. A survey in Scotland showed that the proportion was $45 \%$ isolates from Edinburgh, but was $70 \%$ in similar strains from Glasgow. India has the highest incidence of plasmid-mediated resistance. In $1984,81 \%$ of all Enterobacteriaceae were ampicillin-resistant including $77 \%$ of strains $E$. coli. ${ }^{38}$ In this study, there was a wide distribution of plasmids of many different types. An epidemic of one plasmid type was not being observed and the proportions of individual $\beta$-lactamases was significant. Again, the TEM-1 enzyme was most prevalent, found in $>70 \%$ of strains. Surprisingly, OXA-1 was more common than TEM-2. However, even in an area where resistance was so prevalent, the number of diffent $\beta$-lactamases was quite small. Most of the plasmid-mediated $\beta$-lactamases capable of hydrolysing just ampicillin and first-generation cephalosporins have been found on very few occasions.

About 30 of these plasmid-encoded $\beta$-lactamases capable 
of hydrolysing penicillins and early cephalosporins have been described; however, only five or so are found with any regularity. ${ }^{39}$

The prevalance of the TEM-1 $\beta$-lactamase has forced pharmaceutical companies to seek alternative strategies. This has largely been achieved in two ways: (i) the concurrent use of $\beta$-lactamase inhibitors; (ii) the development of drugs which are resistant to $\beta$-lactamase attack. $\beta$-lactam $\beta$ lactamase inhibitors have proved remarkably successful. There are few reports of plasmid-mediated resistance and these have largely been confined to reports of hyperproduction of TEM $\beta$-lactamases.

Ceftazidime and cefotaxime were considered, at their launch, to be as close to perfection in the design of $\beta$-lactam drugs as was possible to achieve. In one area, it was virtually guaranteed that they would not fail-there would never be plasmid-mediated resistance. In 1982, a change took place which destroyed this guarantee. It was so small that it was missed at the time. A Klebsiella oxytoca strain, originally isolated from the blood and CSF of a baby in a neonatal intensive care unit in Liverpool, was gentamicin-resistant but ceftazidime-sensitive and it produced the TEM-1 $\beta$ lactamase. A subsequent isolate of $K$. oxytoca from this unit showed that it had now become ceftazidime-resistant. In a series of experiments performed 6 years afterwards, the ceftazidime resistance was found to be carried on a $141-\mathrm{kb}$ auto-transferable plasmid. Biochemical analysis showed that the enzyme hydrolysed ceftazidime at a low, but significant, efficiency. The equivalent enzyme could be obtained by a single-step mutation from the TEM- $1 \beta$ lactamase and the Liverpool enzyme was designated TEME2. ${ }^{40}$ Most of these enzymes have been found in continental Europe. In 1983, three strains of $K$. pneumoniae and one of Serratia marcescens were isolated which conferred resistance to cefotaxime. The $\beta$-lactamase was plasmid-mediated and a modification of the ubiquitous klebsiella enzyme, SHV$1{ }^{41} \mathrm{~A}$ glycine residue at position 236 had changed to serine. There followed an explosion of reports of new, plasmidmediated extended-spectrum $\beta$-lactamases.

There are now nearly as many plasmid-mediated extended-spectrum $\beta$-lactamases as there are plasmid-mediated $\beta$-lactamases capable of hydrolysing merely ampicillin or early cephalosporins. Almost all of them are derivatives of TEM-1/2 or SHV-1 $\beta$-lactamases. The maximum number of mutations is three amino acids from TEM-1, TEM-2 or SHV-1 $\beta$-lactamases.

It is difficult to assess whether these enzymes are clinically of great significance. Certainly, there have been outbreaks of resistance caused by these $\beta$-lactamases. The best documented was the epidemic of TEM-3 in $K$. pneumoniae strains isolated in French hospitals. This enzyme was found in nearly 500 strains. $^{42}$ Recently, there has been an equivalent epidemic of bacteria containing TEM-like enzymes in the USA ${ }^{43}$ Generally, the emergence of these $\beta$ lactamases has been sporadic and localised, the vast majority of enzymes being found on very few occasions. This may reflect different localised usages of extended spectrum $\beta$ lactam agents, in particular those related to ceftazidime and cefotaxime.

Payne and Amyes ${ }^{44}$ have grouped these $\beta$-lactamases according to their hydrolysis properties (table II), in a similar manner to the Richmond and Sykes Scheme. ${ }^{26}$

In Group 1 , there are enzymes which hydrolyse both ceftazidime and cefotaxime poorly. In most cases, they hydrolyse cefotaxime with slightly greater efficiency than ceftazidime-this is paradoxical as they confer greater resistance to ceftazidime, which probably results from the superior penetration of cefotaxime.

Group 2 consists of those enzymes capable of hydrolysing ceftazidime more efficiently than cefotaxime and, generally, confer much higher levels of resistance to this drug. Some would not produce clinically significant resistance to cefotaxime as the level of resistance is insufficient.

Group 3 is the largest group and comprises those enzymes that hydrolyse cefotaxime more efficiently than ceftazidime. However, probably for reasons similar to those with the Group 1 enzyme, resistance to cefotaxime is rarely higher than ceftazidime. We have divided this group into (a) those derived from TEM enzymes, (b) all the SHV-derived extended-spectrum $\beta$-lactamases, and (c) two enzymes-one from Japan and one from India - of unknown origins.

All these enzymes confer little, if any, significant resistance to the combination of a $\beta$-lactam agent and $\beta$-lactamase inhibitor, particularly clavulanic acid. Therefore, such combinations should remain effective. However, a new plasmid-mediated $\beta$-lactamase which confers resistance, not only to extended-spectrum $\beta$-lactam agents but also to $\beta$ lactam/ $\beta$-lactamase inhibitor combinations, has recently been identified. This enzyme, called BIL-1, appeared in a clinical isolate of $E$. coli in Pakistan. ${ }^{45}$ The pI of this enzyme was extraordinarily high at $\mathrm{pI} 8.8$ and thus it could have been confused with the induced $\beta$-lactamase of $E$. coli, which is believed to account for the CEP- 1 enzyme. ${ }^{46}$ The CEP-1 $\beta$-lactamase has a pI of 8.2 and was shown to be quite distinct from BIL-1. On the other hand, the BIL-1 $\beta$ lactamese does have a very similar pI to the Enterobacter

Table II. Plasmid-mediated extended-spectrum $\beta$-lactamases

\begin{tabular}{|c|c|c|c|c|}
\hline Group 1 & Group 2 & Group 3 & Group 4 & Unassigned \\
\hline $\begin{array}{l}\text { TEM-E1 } \\
\text { TEM-E2 } \\
\text { TEM-E4 } \\
\text { TEM-7 } \\
\text { CAZ-3 } \\
\text { CAZ-lo }\end{array}$ & $\begin{array}{l}\text { TEM-E3 } \\
\text { TEM-6 } \\
\text { TEM-9 } \\
\text { TEM-10 } \\
\text { CAZ-7 } \\
\text { CAZ-hi }\end{array}$ & $\begin{array}{l}\text { TEM-derived } \\
\text { TEM-3 } \\
\text { TEM-4 } \\
\text { TEM-5 } \\
\text { CAZ-2 } \\
\text { CAZ-6 } \\
\text { SHV-derived } \\
\text { SHV-2 } \\
\text { SHV-3 } \\
\text { SHV-4 } \\
\text { SHV-5 } \\
\text { Unknown } \\
\text { FEC-1 } \\
\text { DJP-1 }\end{array}$ & BIL-1 & $\begin{array}{l}\text { FUR } \\
\text { MJ-1 } \\
\text { MJ-2 } \\
\text { Unamed 1 } \\
\text { Unamed } 2\end{array}$ \\
\hline
\end{tabular}

Group 1, poor hydrolysis of cefotaxime and ceftazidime.

Group 2, better hydrolysis of ceftazidime than cefotaxime.

Group 3, better hydrolysis of cefotaxime than ceftazidime.

Group 4, confers resistance to all cephalosporins and clavulanic acid. 
cloacae type $\mathrm{A}$ chromosomal $\beta$-lactamase. In any case, this enzyme appears to result from a chromosomal gene, encoding a Bush class $1 \beta$-lactamase, migrating into a plasmid vector.

The BIL-1 $\beta$-lactamase has virtually no hydrolytic activity against cefotaxime, ceftazidime, cefuroxime or even ampicillin. It does possess activity against nitrocephin and cephaloridine. It has approximately the same relative efficiency of hydrolysis against these two substrates as the ubiquitous TEM-1. The inhibition properties of BIL-1 are much more interesting. It is readily inhibited, and, therefore, binds ampicillin cefuroxime and ceftazidime. It is 4000 times less sensitive to inhibition by clavulanic acid.

There are five enzymes that do not fit into the classification scheme, mainly because there are insufficient data. It is not yet known from where many of these enzymes are derived, and only one has been found on more than two occasions. New enzymes are being discovered constantly and will be entered into this scheme. It is, of course, vital to know the biochemical relationships, because this probably reflects the selective pressures. However, with most resistance mechanisms, classification often takes account of similarities in nucleotide or amino-acid sequences. This requires full gene sequencing to identify the relationships and will be of particular interest with the SHV- and TEM-derived enzymes.

With the SHV-1 enzymes, the relationships are welldefined and are shown in fig. 2. Each box represents a single amino-acid mutation. Therefore, it is easy to see how SHV1 led to SHV-2 and that SHV-4 was derived either through SHV-3 or SHV-5. All the intervening enzymes have been found in the clinical environment.

The relationships between the TEM-enzymes are much more complicated (fig. 3). Again, each box represents a single amino-acid mutation. It can probably be assumed that the mutation between TEM-1 and TEM-2 occurred before the later enzymes emerged and that the change at amino-acid position 37 does not occur with the extendedspectrum $\beta$-lactamases. Therefore, all those mutations in the top half arose from TEM- 1 and those in the bottom half from TEM-2. Unlike the SHV enzymes, most of the intermediates have not yet been identified. The laboratoryselected $\beta$-lactamase, TEM-101, ${ }^{47}$ a mutation of TEM-1, may well be the TEM-E2 we found in the Liverpool $K$. oxytoca isolate $;^{40}$ but whether TEM-9, for instance, is derived from intermediate $A$ or $D$ is not known.

Plasmid-mediated $\beta$-lacatamases are a vast array of

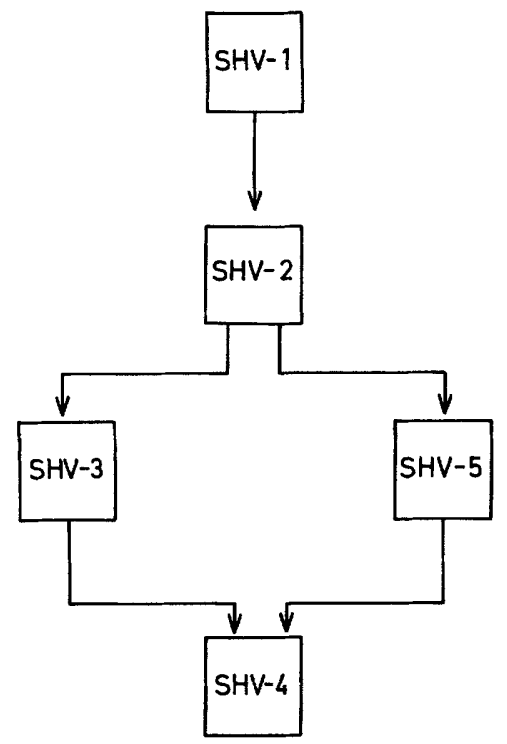

Fig. 2. Diagrammatic representation of the relationships between the SHV-derived $\beta$-lactamases. Each box represents a single aminoacid change.

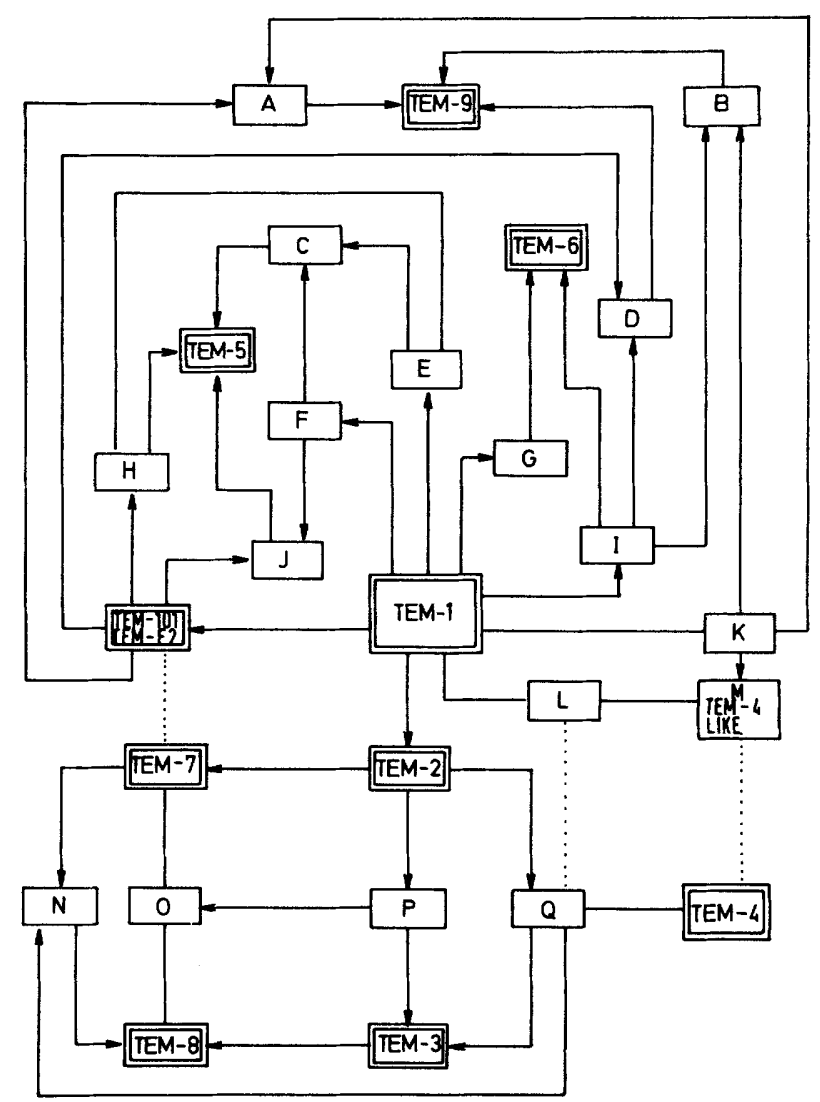

Fig. 3. Diagrammatic representation of the relationships between the TEM-derived $\beta$-lactamases. Each box represents a single aminoacid change.

enzymes; there are nearly 60 distinct enzymes. It is almost certain that many more will be identified. The immediate potential clinical threat comes from the extended-spectrum $\beta$-lactamases; however, we must wait to see which, if any, of these enzymes will emerge as the successor to TEM-1.

\section{RESISTANCE TO THE 4-QUINOLONES}

\section{S. Lewin}

Department of Medical Microbiology, University of Edinburgh Medical School, Teviot Place, Edinburgh, EH8 9AG

The 4-quinolones are chemically synthesised compounds whose principal target is the enzyme DNA gyrase (E.C. number 5.99.1.3), the only bacterial enzyme capable of introducing negative supercoils into DNA. ${ }^{48}$ DNA supercoiling plays an important role in bacterial metabolism-it compacts the chromosome and is involved in the regulation of gene transcription ${ }^{49}$ as well as the bacterial response to the environment. ${ }^{50}$ The enzyme is a tetramer consisting of two $A$ and two B subunits. ${ }^{48}$ The $A$ subunit cuts both strands of DNA simultaneously at intervals four base pairs apart and holds the strands apart but covalently bound to the enzymes. The B subunit, using ATP for energy, then introduces a negative supercoil into the DNA and the A strand then reseals the two strands.

The first 4-quinolone, nalidixic acid, was synthesised almost 30 years ago. Its antimicrobial spectrum is limited to the Enterobacteriaceae; it is useful for the treatment of urinary tract and enteric infections. The antimicrobial spectrum of the 4-quinolones was extended by the discovery that the addition of a piperazine at $\mathrm{C} 6$ and fluorine at $\mathrm{C} 7$ to the common 4-oxo-1,4-dihydroquinolone skeleton caused a 1000 -fold improvement in antimicrobial activity. Bacterial species intrinsically resistant to nalidixic acid are susceptible 
to these new fluoroquinolones and, in the $1980 \mathrm{~s}$, compounds such as pefloxacin, norfloxacin, ciprofloxacin, enoxacin and ofloxacin, active against a wide range of bacterial species, became available for clinical use.

The increasing therapeutic potential of these antimicrobial agents has caused considerably interest in the mechanisms by which bacterial resistance to the 4-quinolones is mediated. Bacterial resistance to antimicrobials can be mediated either via a plasmid or a chromosomal mutation.

Plasmids often carry several genes conferring resistance to several antimicrobial agents, therefore, in clinically important bacteria, tend to be the main reservoir of resistance to most antimicrobial agents. This is not the case with the 4quinolones as, unlike other commonly used antimicrobial agents, plasmid-mediated resistance to the 4-quinolones has yet to be identified in clinical isolates. It should be noted that plasmids have been associated with nalidixic acid resistance in shigellas isolated from the Indian subcontinent but they did confer resistance to the 4-quinolones. ${ }^{51.52}$ Although plasmid-mediated 4-quinolone resistance has yet to be found clinically, a potential mechanism of resistance, which may involve drug accumulation, has recently been reported.

The nor $A$ gene identified in Staphylococcus aureus codes for a $50-\mathrm{Kda}$ protein which appears to be membrane associated and confers high-level resistance to hydrophilic fluoroquinolones. ${ }^{53.54}$ This gene has been cloned into plasmid pBR322. ${ }^{53.54}$ When a quinolone-susceptible strain, Escherichia coli $\mathrm{HB101}$, was transformed with the recombinant plasmid, it developed resistance to the 4-quinolones. The MICs of hydrophilic drugs such as enoxacin, norfloxacin, ciprofloxacin and ofloxacin increased 8 to 64 fold whereas only a two-fold increase was observed for the hydrophobic 4-quinolones nalidixic acid and sparfloxacin. ${ }^{53.54} \mathrm{Kaatz}$ et al . have also recently identified a mutation similar to nor $A$ in an isolate of $S$. aureus which conferred resistance on an $E$. coli recipient strain when it was cloned on to a plasmid (unpublished results). Thus, a mechanism by which a plasmid could confer resistance to the 4quinolones has been identified although it has yet to be found in a clinical isolate.

The probability of plasmid-mediated 4-quinolone resistance arising via the two other two mechanisms that have been identified for other classes of antibacterial agents seems low. A drug destruction mechanism appears unlikely as the 4-quinolones are synthetic agents. A 4-quinolone resistant DNA gyrase coded by a plasmid would also seem an unlikely candidate because genetic studies have shown that quinolone sensitivity is dominant over quinolone resistance in gyrase genes, ${ }^{55}$ Indeed, transformation of quinolone resistant strains with plasmids carrying quinolone susceptible gyrase genes have been used to identify alterations in DNA gyrase as the cause of resistance to the 4-quinolones in gramnegative bacteria. ${ }^{55-57}$

As plasmid-mediated quinolone resistance has yet to be identified in a clinical strain, chromosomal mutations are the only mechanism by which bacteria are able to develop resistance to the 4-quinolones during therapy. Chromosomally-mediated resistance to the 4-quinolones can occur by one of two mechanisms - either an alteration in the target enzyme, DNA gyrase, or a mutation that reduces drug accumulation

In most species investigated so far, high-level resistance to all 4-quinolones appears to be conferred by mutations in the gyrA gene which codes for the A subunit of DNA gyrase. GyrA mutations confer high-level cross-resistance to all 4quinolones but do not seem to be associated with resistance to other, unrelated antibacterial agents. Such mutations have been identified in $E$. coli (cfxA, gyrA, nalA, nfxA), ${ }^{55,58,59}$ Pseudomonas aeruginosa (nalA, cfxA), ${ }^{60-62}$ Haemophilus influenzae, ${ }^{63}$ Citrobacter freundii ${ }^{64}$ and Serratia marcescens. ${ }^{65}$
The gyr A genes of $E$. coli, Bacillus subtilis, $S$. aureus and Klebsiella pneumoniae have been sequenced revealing close homology between the gyrases of different species. ${ }^{6-68}$ Nucleotide sequence analysis performed on 10 spontaneous quinolone-resistant gyr $A$ mutants of $E$. coli $\mathrm{KL}^{16} 6^{69}$ showed that quinolone resistance appeared to be conferred by point mutations within a small region between amino acids 67 and 106 near the $\mathbf{N}$ terminus of the $A$ subunit. Six of the 10 mutants possessed a substitution at amino acid 83 , a serine. This mutation has also been identified in a clinical isolate of $E$. coli that developed resistance during enoxacin therapy. ${ }^{70}$ In $S$. aureus, this serine is located one amino acid further on at position 84 . There is also a serine at amino acid 85 (aa 84 is alanine in $E$. coli) and substitution of either amino acid was found to be the cause of quinolone resistance in clinical isolates of $S$. aureus. ${ }^{71}$ Furthermore, high level ciprofloxacin resistance in $S$. aureus (MIC $>\mathrm{mg} / \mathrm{L}$ ) was found to be associated with substitution of both serines. ${ }^{71}$ It is interesting to note that all of the mutations conferring quinolone resistance are situated close to the tyrosine at amino acid 122 of the A subunit that is covalently bound to DNA when the enzyme breaks the phosphodiester bonds of DNA. ${ }^{48}$ Although little is known about the quinolone-gyrase-DNA complex, it would seem that the alterations in amino acid residues result in disruption of key interactions of the complex.

Mutations in the B subunit of DNA gyrase coded by the gyr $B$ gene have been shown to cause 4-quinolone resistance in $E$. coli and $P$. aeruginosa. ${ }^{55,56}$ However, unlike gyr $A$ mutations, these do not always cause cross-resistance to all 4-quinolones. The nal31 mutation in $E$. coli ${ }^{72}$ confers resistance to the 4-quinolones lacking a $C 7$ piperazine while rendering bacteria hypersensitive to 4-quinolones possessing this substituent. This phenomenon results from the mutation increasing the negative charge of the B subunit, increasing its attraction for the positively charged piperazine group. ${ }^{73}$

The 4-quinolones must penetrate bacteria to gain access to their target DNA gyrase. Therefore, a reduction in the ability of the 4-quinilones to enter bacteria results in decreased bacterial susceptibility. The 4-quinolones penetrate bacteria by diffusion through porins in the outer membrane of gram-negative bacteria. The hydrophobic 4quinolones such as nalidixic acid are also able to penetrate the bacterium through the phospholipid bilayer. ${ }^{73,74}$ Active transport may also play a role in bacterial accumulation of the 4-quinolones as endogenous active efflux of norfloxacin has been demonstrated at the inner membrane of $E$. coli and $P$. aeruginosa. ${ }^{75-76}$

In gram-negative bacteria, mutations affecting 4-quinolone permeability have been identified in $E$. coli ( nal $B, n f x B$, nor $B, c f x B$ ), Salmonella, Pseudomonas (nalB, $c f x B$ and $n f x B$, $q r 1, q r 2)$, Klebsiella and Serratia spp. and have been reviewed recently. ${ }^{52,77}$ Unlike alterations in DNA gyrase, which confer only cross-resistance to other 4-quinolones, resistance caused by the reduction in 4-quinolone accumulation can be associated with decreased sensitivity to unrelated antibacterial agents. Mutations in $E$. coli which confer resistance to the 4-quinolones by an impermeability mechanism are associated with alterations in outer-membrane porin $F$ (ompF). Both inactivation of the $o m p F$ gene and mutations in regulatory genes controlling expression of $o m p F$ at a posttranscriptional level can cause 4-quinolone resistance; e.g., cf $x B$ appears to be an allele of the mar $A$ gene which confers resistance to tetracyclines and chloramphenicol as well as to the 4-quinolones. ${ }^{78}$

In $P$. aeruginosa, resistance to the 4-quinolones resulting from reduced drug accumulation has been associated with alterations in a wide range of outer-membrane proteins. ${ }^{52}$ Resistance to the 4-quinolones can be associated with crossresistance to other antibacterial agents; e.g., the $Q r l$ and $Q r 2$ mutations associated with a reduction in ompG and an 
antigenically related $40-\mathrm{K}$ da outer-membrane protein conferred resistance to some $\beta$-lactam agents, chloramphenicol and tetracycline, as well as to the 4-quinolones. ${ }^{76}$ However, this is not always the case as, for example, unstable low-level resistance to the 4-quinolones in this species associated with the alteration or loss of a $31-32-\mathrm{Kda}$ outer-membrane protein did not confer cross-resistance to antibacterials unrelated to the 4-quinolones. ${ }^{79}$

Fukuda et $a l .{ }^{80}$ have recently identified a new resistance mechanism in $P$. aeruginosa strain PAO associated with reduced drug permeability. The $n f x C$ mutation mapped near catA (46 min) on the PAO chromosome and caused a 10- to 32-fold decrease in susceptibility to ciprofloxacin, ofloxacin, norfloxacin and fleroxacin. It was associated with increased expression of a 50-Kda protein and decreased expression of a $46-\mathrm{Kda}$ protein. The $n f x C$ mutation was associated with cross-resistance to imipenem and chloramphenicol but rendered bacteria highly susceptible to other extended spectrum cephalosporins and to aminoglycosides. This mutation was thought to be clinically significant as quinolone-resistant $\boldsymbol{P}$. aeruginosa that are resistant to imipenem but susceptible to other $\beta$-lactam agents have been isolated from patients. ${ }^{80}$

In $E$. coli and $P$. aeruginosa, resistance to the 4-quinolones has been associated with alterations in the expression of lipopolysaccharides. ${ }^{52,77}$ Hence, resistance manifested by reduced drug accumulation does not result solely from changes in the outer-membrane proteins. The discovery of an active efflux system for the 4-quinolones suggests that another class of drug mutations, which confer resistance by reducing 4-quinolone accumulation, may exist, although they have yet to be identified. This might be similar to tetracycline resistance, in which the drug efflux system works with enhanced efficiency. Finally, much less information exists about resistance to the 4-quinolones resulting from reduced drug accumulation in gram-positive bacteria. The best characterised mutation is the nor $A$ mutation in $S$. aureus discussed previously. ${ }^{54,55}$

The development of resistance to the modern fluorinated 4-quinolones during therapy has been shown to have occurred in a wide range of bacterial species. ${ }^{52,77}$ These clinical reports indicate that it is possible for most bacterial species to develop resistance to the 4-quinolones during therapy. However, extrapolation of the frequency at which resistance to the fluoroquinolones is likely to develop clinically from these isolated reports is not possible. The monitoring of bacterial susceptibility to the 4-quinolones once they have been introduced serves to provide such epidemiological information. Several large scale studies have monitored the susceptibility of bacterial pathogens to the 4-quinolones since they have become available and, generally, very little resistance to the modern 4-quinolones has been observed. ${ }^{52,81,82}$

Kresken and Wiedemann ${ }^{81}$ monitored nalidixic acid resistance in the Federal Republic of Germany, Austria and Switzerland from 1975 to 1986 , with particular emphasis on the period between 1983 and 1986 when ofloxacin and norfloxacin became available in these countries. Despite a marked increase in the use of the 4-quinolones during this period, resistance in Enterobacteriaceae, $S$. aureus or Enterococcus faecalis did not increase. $P$. aeruginosa was an exception; between 1983 and 1986, the percentage of 4quinolone-resistant strains increased from $3 \%$ to $10 \%$. Another survey performed in the Federal Republic of Germany by Grimm, ${ }^{82}$ testing over 100000 bacterial strains isolated from both hospitals and general practice between 1986 and 1987, found similar results to those of Kresken and Wiedemann $^{81}$ for Enterobacteriaceae. However, Grimm ${ }^{82}$ report a significant increase in the incidence of 4-quinolone resistance in staphylococci, particularly amongst multiresistant $S$. epidermidis. There have also been other reports of high incidence of ciprofloxacin resistance in methicillinresistant $S$. aureus (MRSA) isolated in hospitals. ${ }^{52,83}$ This resistance does not necessarily appear to develop during therapy of the MRSA infection may be associated with use of ciprofloxacin for treatment of a pathogen other than MRSA. ${ }^{52,83}$ It has been suggested that ciprofloxacin resistance can develop in colonising MRSA which then subsequently spread to other patients in the hospital. ${ }^{83}$ Problems may also exist in other bacterial species. The frequency of resistance to the 4-quinolones may be increasing in Bacteroides fragilis and Ser. marcescens. Surveys in Japan have reported high incidences of quinolone resistance in these species. ${ }^{66,84}$

In conclusion, the clinical incidence of 4-quinoloneresistant bacteria is still relatively rare, although it seems to be occurring with increasing frequency in certain species such as $P$. aeruginosa and staphylococci (particularly multiresistant organisms). Resistance is not plasmid-mediated at present although a potential mechanism involving reduced accumulation has now been identified. Resistance to the 4 quinolones occurs through chromosomal mutations resulting in an altered target (DNA gyrase) or reduced drug accumulation (particularly associated with alterations in the outer-membrane porins).

\section{MECHANISMS AND EPIDEMIOLOGY OF AMINOGLYCOSIDE RESISTANCE}

\section{N. M. Brown and D. S. Reeves}

Department of Medical Microbiology, Southmead Hospital, Westbury-on-Trym, Bristol

\section{Introduction}

The aminoglycoside-aminocyclitol antibiotics have remained valuable agents for treating serious infections since their introduction, despite the development of newer broad spectrum and less toxic antibiotics. The emergence of resistance to them has followed their widespread use and, although generally it still remains at a low level for most organisms, is important for the increased mortality, morbidity and expense it causes. This is particularly true for resistant strains having the ability to spread rapidly in institutions causing outbreaks of nosocomial infection. ${ }^{85}$

The uptake of the aminoglycoside antibiotics by the bacterial cell and their mechanisms of action has been shown to be a complex process, as yet incompletely understood. Nevertheless, some discussion of these events is helpful in understanding the different mechanisms of aminoglycoside resistance.

\section{Aminoglycoside uptake and action}

The uptake of aminoglycosides by bacterial cells has been most extensively studied with streptomycin and gentamicin. It differs from the uptake of most antibiotics in that it is active (energy-dependent), and has been divided into three phases. The first phase of uptake is the attraction and binding of the antibiotic to the cell outer membrane of gramnegative rods, and is rapid and passive. The second and third phases have been named energy-dependent phases I (EDP-I) and II (EPD-II). The initial passive uptake of aminoglycoside is thought to depend on the electrical potential across the outer membranes. Aminoglycosides are cationic and are, therefore, attracted to anions on the cell surface and across the outer membrane by the internally negative electrical potential, passing through the porin channels of gram-negative cells or water filled interstices of gram-positive cells. In Pseudomonas aeruginosa, which has a less permeable outer membrane, a model has been proposed whereby the aminoglycoside binds to the negatively charged 
magnesium binding sites on the membrane surface, causing disruption of the membrane barrier and facilitating entry into the cell of aminoglycoside. ${ }^{86}$ The extent and rate of ionic uptake depends on the size of the electrical potential gradient across the outer membrane, and a number of inhibitors which reduce ionic binding and diffusion have been described. ${ }^{87}$

The EDP-I appears to be comparatively slow, and is thought to represent the transport of the aminoglycoside across the cytoplasmic membrane to come into contact with the ribosome, perhaps on transporter molecules. It precedes any of the intracellular events leading to cell death and appears to be the rate limiting step in uptake.

The EDP-II occurs as the aminoglycoside binds to specific binding sites on the $30 \mathrm{~S}$ ribosome and the initiation of protein synthesis is disrupted. This leads to changes in the permeability of the cell membrane and a secondary, rapid escalation in antibiotic uptake, cell disorganisation and, ultimately, cell death.

In aerobic gram-negative bacteria, the kinetics of cell killing has been shown to be biphasic. ${ }^{88}$ An initial phase of cell death occurs soon after the aminoglycoside is administered and is thought to be associated with the ionic binding to the cell. It appears to be very rapid and related to the concentration of the antibiotic. A second phase of killing is much slower and independent of drug concentration. Such findings show the importance of obtaining adequate peak aminoglycoside concentrations and have been used as an argument in favour of single, large, once-daily dosage regimens. However, despite this, the slower energy-dependent phases of uptake are the most important phases in the bactericidal action of aminoglycoside antibiotics. ${ }^{89}$ Many antibiotics acting on protein synthesis, e.g., chlorampheni$\mathrm{col}$, are bacteriostatic. They do not have the same complex energy-dependent uptake mechanisms as the aminoglycosides, and the interference in protein synthesis by many of these agents is reversible. The uptake of aminoglycosides is irreversible in vitro unless the cell membrane is destroyed by an agent such as toluene, and the rapid influx of antibiotic occurring in EDP-II appears to be the important step in the irreversible disruption of protein synthesis conferring cidal activity. ${ }^{90}$

\section{Mechanisms of resistance to aminoglycosides}

There are three mechanisms by which resistance of bacteria to aminoglycoside antibiotics may occur-enzymic modification, deficiency of uptake or accumulation, and modification of the ribosomal target site.

Enzymic modification. This is the most common and clinically important cause of acquired aminoglycoside resistance. Enzymes may modify the aminoglycoside by various mechanisms-particularly $\mathrm{N}$-acetylation, $\mathrm{O}$-nucleotidylation or O-phosphorylation. A number of different aminoglycoside modifying enzymes (AME) have been identified and the nomenclature for their description consists of a three letter code according to their mode of actionaminoglycoside acetyltransferase (AAC), aminoglycoside phosphoryl-transferase (APH) and aminoglycoside adenyltransferase or nucleotidylase (AAD or ANT). The site of action of the enzyme on the aminoglycoside molecule is denoted by a number in parenthesis, e.g., AAC ( $\left.2^{\prime \prime}\right)$ represents acetylation of the $2^{\prime \prime}$-amino group. Further characterisation may be given by the addition of roman numerals to differentiate enzymes of similar actions. Thus, potentially, an aminoglycoside may be modified at more than one site and, therefore, be a substrate for more than one enzyme. Similarly, an enzyme may have several different substrates.

Most genes coding for AMEs are plasmid specified, and many are known to be carried on transposons. Plasmid transfer may occur by conjugation, transduction or transfor- mation and a single plasmid may carry more than one AME gene. More rarely, the enzyme is chromosomally specified, and this has been described in Serratia spp., Acinetobacter spp., Pseudomonas spp., Staphylococcus aureus and some streptococci.

In contrast to some other antibiotic-modifying enzymes, e.g., the $\beta$-lactamases, AMEs appear to be virtually completely intracellular. Very little enzyme or modified aminoglycoside can be found outside the cell; therefore, extracellular antibiotic is still active. Although the exact location of the AME within the cell is not known, it is thought to be closely associated with the cytoplasmic membrane. ${ }^{91}$ Modification of the aminoglycoside substrate at this site could confer resistance by preventing binding to the specific ribosomal binding sites or by interfering with aminoglycoside accumulation. As has been discussed, these processes are closely related.

Enzymes are thought to be constitutively expressed. However, the amount of enzyme produced and the rate of substrate action may be variable. It has been postulated that within each bacterial cell there is competition between the rate of aminoglycoside modification and the rate of transport of aminoglycoside across the cytoplasmic membrane during EDP-I; this being the rate limiting step. ${ }^{91}$ If uptake exceeds modification the cell may be killed even though it possesses a mechanism of resistance. With exposure to aminoglycoside, resistant bacterial cells with a higher rate of substrate modification may emerge, perhaps due to selection of bacteria with higher gene copy numbers and hence sufficient enzyme so that modification exceeds aminoglycoside accumulation. At present it is not thought that true enzyme induction occurs.

Deficiency of uptake or accumulation. Because of the complex nature of aminoglycoside uptake there is great potential for resistance to occur by this mechanism. Mutants with altered cell-membrane structure or cellular metabolism could interfere with the aminoglycoside accumulation described above. It is becoming increasingly recognised that isolates that are resistant to aminoglycosides by these mechanisms exist and may have clinical importance.

Most organisms intrinsically resistant to aminoglycosides are unable to accumulate sufficient antibiotic. Strict anaerobes that respire without a functioning electron-transport chain, for example, are unable to drive the energy-requiring phases of uptake and cannot maintain an adequate negative internal potential for uptake to occur. Likewise, some fermentative bacteria, such as streptococci, may exhibit low level resistance due to incomplete electron-transport systems. ${ }^{92}$ In some clinical isolates of $\boldsymbol{P}$. aeruginosa showing resistance, an altered lipopolysaccharide structure in the cell membrane has been described ${ }^{92}$ similar findings have been reported with other organisms, particularly Klebsiella pneumoniae. Such resistance, as described in $P$. aeruginosa, is chromosomally specified and non-transferable. It is stable in vitro and independent of exposure to aminoglycoside. In general, resistance of this type affects a wide range of aminoglycosides and is of low level. High concentrations of aminoglycoside may overcome the permeability barrier and render the organism sensitive. This is in contrast to enzymic modification, which tends to affect specific aminoglycosides and usually produces high-level resistance.

Recently, there has been considerable interest in adaptive resistance as a result of exposure to low levels of aminoglycosides. This has been described both in vitro and in vivo. ${ }^{93}$ Exposure to one dose of aminoglycoside may produce resistant variants of an organism that have altered metabolism and, consequently, impaired aminoglycoside accumulation. This has been shown to occur most readily with $P$. aeruginosa, but also with Escherichia coli and $S$. aureus, and, as with the impermeability resistance described above, affects a wide range of aminoglycosides and is of low level. 
However, such isolates quickly revert to susceptibility when exposure to the aminoglycoside is removed. This suggests that they are not simply resistant mutants selected by antibiotic exposure. Often, colonies are readily identifiable by their small size, slow growth and atypical morphology, ${ }^{93}$ which could also reflect intracellular metabolic changes. Such adaptive resistance may have clinical relevance to cases of treatment failure in conditions requiring prolonged or repeated aminoglycoside therapy, e.g., endocarditis and cystic fibrosis, and could be difficult to detect in the laboratory as isolates may revert to susceptibility at initial isolation.

Modification of ribosomal target site. Aminoglycosides interfere with the initiation of protein synthesis by binding to specific binding sites on the $30 \mathrm{~S}$ ribosome. As yet, mutations affecting this specific target site do not appear to have great clinical importance. Experimental and clinical isolates showing resistance to streptomycin and spectinomycin by this mechanism have been described, and are thought to arise by single step mutations at the StrA locus. Although mutations near to this site may produce resistance to other aminoglycosides, this has not been seen in clinical isolates. $^{93}$

\section{The epidemiology of aminoglycoside resistance}

It is not surprising that resistance to aminoglycosides is becoming increasingly recognised, as these agents have been widely used in hospitals for more than 20 years, not only for treatment but also for prophylaxis. They are also used in veterinary practice and in commercial processes involving animals. ${ }^{94}$ Several multicentre study groups have documented the prevalence of aminoglycoside resistance and also the mechanisms of resistance. These include groups in the UK, ${ }^{95}$ Europe $^{96,97}$ and the USA. ${ }^{98}$ Such collaborative studies are essential as the prevalence of aminoglycoside resistance in each individual hospital is low, but they have generally only been able to give a single snapshot of patterns of resistance (the point prevalence). More information can be obtained from studies of the prevalance of resistance over a period time, ${ }^{99,100}$ or studies that have been repeated, such as the European Study on Antibiotic Resistance (ESGAR) reports of 1987 and $1990 .{ }^{96,97}$ A summary of some of these reports is shown in table III. Variations in the resistance level can be found, not only between countries, but also between laboratories participating in individual studies. One striking difference is the increasing resistance from
Northern to Southern Europe (table IV). The USA has resistance levels approaching those of Southern Europe. However, care must be taken when comparing these studies as the isolates examined come from a variety of clinical sources. The majority of studies have looked at consecutive blood-culture isolates, but some have included all clinical isolates or urine isolates. Also, the distribution of organisms varies between studies; those finding a higher incidence of Providencia, Serratia and Acinetobacter spp. and coagulasenegative staphylococci have reported a high level of aminoglycoside resistance. Differences in the geographical pattern of resistance may reflect different patterns of aminoglycoside usage. Similarly, the isolation of organisms more likely to be aminoglycoside-resistant, such as those listed above, may reflect selection secondary to antibiotic exposure.

In all studies, the most common mechanism of aminoglycoside resistance is modification by enzymes. Impermeability resistance accounts for $<10 \%$ of resistant isolates and is seen most frequently in non-aeruginosa Pseudomonas spp. ${ }^{95}$ The distribution of AMEs varies from country to country. In Europe as a whole, the most common AMEs in gramnegative bacilli are ANT( $\left.2^{\prime \prime}\right), \operatorname{AAC}(3) \mathrm{V}$ and $\mathrm{ACC}\left(6^{\prime}\right) \mathrm{II}$, and in staphylococci the double-acting AME APH(2")/AAC(6') combined and ANT $\left(4^{\prime}\right) .{ }^{96}$ Combinations of AMEs are common and a wide variety of different enzymes is seen, especially in isolates from Southern Europe where AAC(6')I, either alone or in combination, is responsible in part for higher resistance levels. In the $\mathrm{UK}$, the most common enzymes are AAC(3) and ANT( $\left.2^{\prime \prime}\right)$ in gram-negative bacilli and APH $\left(2^{\prime \prime}\right) / \mathrm{AAC}\left(6^{\prime}\right)$ in staphylococci. ${ }^{95,99}$ Similar findings have been described from the USA and Australia. This differs from the Far East, where AAC(6") is most common, and Chile, where $>90 \%$ of aminoglycoside-resistant isolates possess ACC(3). ${ }^{101}$ Again, these differences may reflect pressure due to antibiotic usage. In Japan, for example, the high usage of kanamycin and dibekacin may have encouraged the selection of AAC $\left(6^{\prime}\right)$, which causes resistance to this group of antibiotics, whereas AAC(3), which confers resistance to gentamicin, sisomycin and netilmicin, is rarely seen. The presence of a single enzyme in resistant Chilean isolates may represent the distribution of a single R-plasmid in a hospital. ${ }^{101}$ In studies from other countries, however, there has been a tendency in more recent surveys to find an increasing number of different AMEs, often in combination. ${ }^{102,103}$ Although selection pressure from hospital aminoglycoside usage may be the most important factor controlling this, other factors, such as spread of resistance through animals may also be significant. ${ }^{94}$

Table III. Gentamicin resistance $(\%)$ described in some recent studies

\begin{tabular}{|c|c|c|c|c|c|c|c|c|c|}
\hline Study reference & Finland $^{102}$ & Sweden ${ }^{100}$ & $\begin{array}{l}\text { St Thomas's } \\
\text { Hospital UK } 99\end{array}$ & Saudi Arabia ${ }^{103}$ & \multicolumn{2}{|c|}{ Europe $^{97}$} & \multicolumn{2}{|l|}{$\mathrm{UK}^{95}$} & Europe $^{96}$ \\
\hline Number of isolates & 633 & 2027 & 7264 & 5001 & 2578 & 2463 & 970 & 4146 & 3440 \\
\hline Source of isolates & Blood & Blood & All clinical & All clinical & Blood & Urine & Blood & Urine & Blood \\
\hline Escherichia coli & 0 & $\ldots$ & 0.6 & 2 & 3 & 3 & $1 \cdot 6$ & 0.6 & 4 \\
\hline Klebsiella spp. & $5 \cdot 5$ & $\ldots$ & 3 & 9 & ) & 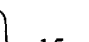 & 1 & $8 \cdot 5$ & ) \\
\hline Citrobacter spp. & $\cdots$ & $\ldots$ & $0 \cdot 5$ & 8 & \} 14 & 15 & $\mathbf{0}$ & 30 & 10 \\
\hline Enterobacter spp. & $\ldots$ & $\ldots$ & 3 & 15 & & & 6 & 4 & ) \\
\hline Serratia spp. & $\cdots$ & $\ldots$ & 0 & 21 & 30 & 54 & 6 & 28 & 28 \\
\hline Providencia spp. & $\ldots$ & $\ldots$ & 73 & 53 & $\ldots$ & $\ldots$ & $\ldots$ & 79 & $\ldots$ \\
\hline Acinetobacter spp. & $\ldots$ & $\ldots$ & 13 & 37 & 56 & 50 & $\ldots$ & $\ldots$ & 65 \\
\hline Pseudomonas spp. & 50 & $\ldots$ & 3 & 27 & 28 & 26 & 6 & 6 & 33 \\
\hline $\begin{array}{l}\text { Total all gram-negative } \\
\text { bacilli }\end{array}$ & $\ldots$ & 1 & 5 & $\cdots$ & 12 & 12 & $3 \cdot 3$ & $2 \cdot 4$ & 12 \\
\hline Staphylococcus aureus & 0.7 & 1 & 3 & $\ldots$ & 12 & 20 & 2 & 5 & 12 \\
\hline $\begin{array}{l}\text { Coagulase-negative } \\
\text { staphylococci }\end{array}$ & 20 & 20 & $\cdots$ & $\cdots$ & 26 & 28 & 29 & 16 & 53 \\
\hline
\end{tabular}


Table IV. Aminoglycoside resistance from European blood-culture isolates

\begin{tabular}{|c|c|c|c|c|c|c|c|c|}
\hline \multirow{2}{*}{ Region } & \multicolumn{4}{|c|}{ Percentage of gram-negative isolates resistant to } & \multicolumn{4}{|c|}{ Percentage of gram-positive isolates resistant to } \\
\hline & Gent & Tob & Net & Ami & Gent & Tob & Net & Ami \\
\hline $\begin{array}{l}\text { Northern Europe } \\
\text { Central Europe } \\
\text { Southern Europe }\end{array}$ & $\begin{array}{r}3 \\
8 \\
24\end{array}$ & $\begin{array}{r}2 \\
7 \\
22\end{array}$ & $\begin{array}{r}4 \\
8 \\
23\end{array}$ & $\begin{array}{r}3 \\
7 \\
15\end{array}$ & $\begin{array}{l}15 \\
32 \\
30\end{array}$ & $\begin{array}{l}18 \\
34 \\
31\end{array}$ & $\begin{array}{r}6 \\
19 \\
17\end{array}$ & $\begin{array}{l}10 \\
28 \\
17\end{array}$ \\
\hline
\end{tabular}

Northern Europe: Sweden Finland, Denmark, Great Britain; Central Europe : Belgium, Netherlands, West Germany, Austria, Switzerland Southern Europe: France, Spain, Portugal, Italy, Greece.

Gent, gentamicin; Tob, tobramycin; Net, netilmicin; Ami, amikacin.

\section{Methods for identification of resistance mechanism}

Some idea as to the mechanism of resistance of an aminoglycoside-resistant isolate can be obtained from the resistance pattern, level of resistance, colonial morphology, and growth, as described above. Most isolates will be resistant by enzymic modification. Identification of the AME is rarely necessary clinically, but may be useful for epidemiology or research. Identification may be presumed by testing susceptibility to the aminoglycoside substrates for the enzyme, and simple methods have been described based upon either $\mathrm{MICs}^{101}$ or inhibition zone diameters. ${ }^{104}$ It is likely that results of these tests will become increasingly difficult to interpret as the frequency of combinations of enzymes increases. Furthermore, some of these methods use, ideally, aminoglycosides not in clinical use and therefore difficult to obtain.

Most other methods for enzyme identification are unlikely to be used by clinical laboratories. Radiolabelled co-factors have been widely used to measure the binding of modified aminoglycoside to cellulose phosphate paper but can give confusing results with some enzyme combinations. High performance liquid chromatography of the reaction products may also be used; this has the advantage of specifically identifying reaction products. Most recently, techniques have concentrated on the genes coding for AMEs. Specific probes have been developed for detecting AME genes, and the polymerase chain reaction can further facilitate this. As techniques improve, these methods will become more sensitive and may prove to be very useful for identifying combinations of AMEs.

\section{GLYCOPEPTIDE RESISTANCE IN GRAM-POSITIVE BACTERIA}

\section{P. E. Reynolds}

Department of Biochemistry, University of Cambridge, Tennis Court Road, Cambridge, CB2 $1 Q W$

\section{Introduction}

Some of the most used antibiotics in clinical medicine are those that affect the bacterial cell wall which is composed of a variety of macromolecules, some of them found uniquely in bacteria. The majority of clinically-important bacteria contain peptidoglycan, which confers rigidity on the bacterium and is the main molecular determinant of cell shape. It is a large, polar molecule which is assembled on the outside surface of the bacterium in three main stages from subunits manufactured inside the cell. The subunits are transferred across the membrane, polymerised to form short polysaccharide chains substituted with unusual peptides which are finally cross-linked to the existing wall by the transpeptidation reactions. This series of reactions leading to the formation of cross-linked peptidoglycan affords a plethora of potential targets for antimicrobial agents. ${ }^{105}$ The presence of a unique amino-sugar and the un-natural D-isomers of two amino acids ensures that these targets are unique to bacteria and that antibiotics interfering with the biosynthetic pathway are likely to be selectively toxic to bacteria. The last two reactions in the pathway (polymerisation and transpeptidation) occur outside the cytoplasmic membrane and, consequently, antibiotics that interfere with these stages of synthesis do not require a transport system to reach the target site. Glycopeptide antibiotics (vancomycin and teicoplanin) inhibit the first of these two reactions (and would also block transpeptidation) by binding tightly to the unique acyl-D-alanyl-D-alanine arrangement of amino acids in the membrane-bound nascent peptidoglycan. ${ }^{106}$

\section{Mechanism of action of glycopeptide antibiotics}

Glycopeptide antibiotics are effective at low concentrations against the majority of gram-positive bacteria, but toxicity problems in the early years of their application precluded their widespread use in spite of their selective action against the peptidoglycan. The introduction of $\beta$ lactamase-stable penicillins resulted in a temporary reduction in the clinical use of vancomycin, but the acquisition of alternative mechanisms of resistance to $\beta$-lactam antibiotics in particular, and an improvement in the purity of the vancomycin preparations, witnessed a resurgence in the use of glycopeptides, particularly against multiresistant staphylococci that are intrinsically resistant to all $\beta$-lactam antibiotics. Glycopeptide antibiotics, including vancomycin and teicoplanin, are large, rigid molecules; they adopt a bracelet-like configuration with a substantial cleft or pocket into which peptides ending in D-alanyl-D-alanine bind firmly, though non-covalently, with almost computerised precision. ${ }^{107}$ It is the mechanism of action of this groupinteraction with a structural component of the cell wall rather than with a target protein-that makes this class of antibiotics unique and reduces the possibility of large-scale resistance emerging in clinical strains. Definitive studies of the interaction of glycopeptides with the target peptides were elucidated with the use of nuclear magnetic resonance spectroscopy, by mass spectrometry followed by model building, and by 3-dimensional reconstruction of the binding sites. ${ }^{108}$ The wall subunit, either attached to its lipid carrier or as part of the growing peptidoglycan chain to which the new subunit will be added, is held firmly by hydrogen bonding to the peptide backbone of the glycopeptide (fig. 4). The space-filling model of the glycopeptide-pentapeptide complex indicates that the sugars in the wall subunit are not immediately adjacent to the glycopeptide molecule, but the peptidoglycan polymerase whose active site must be located close to the sugars is a large molecule in comparison with both the antibiotic and the wall subunit. Presumably, the 
presence of the antibiotic on the subunit prevents the enzyme from being located precisely in the correct position so that it can no longer catalyse the transglycosylation reaction that polymerises the peptidoglycan backbone chain. ${ }^{109}$ In addition to the inhibition of the peptidoglycan polymerase by steric hindrance (fig. 5), binding of glycopeptides to the Dalanyl-D-alanine terminus of the subunit effectively blocks

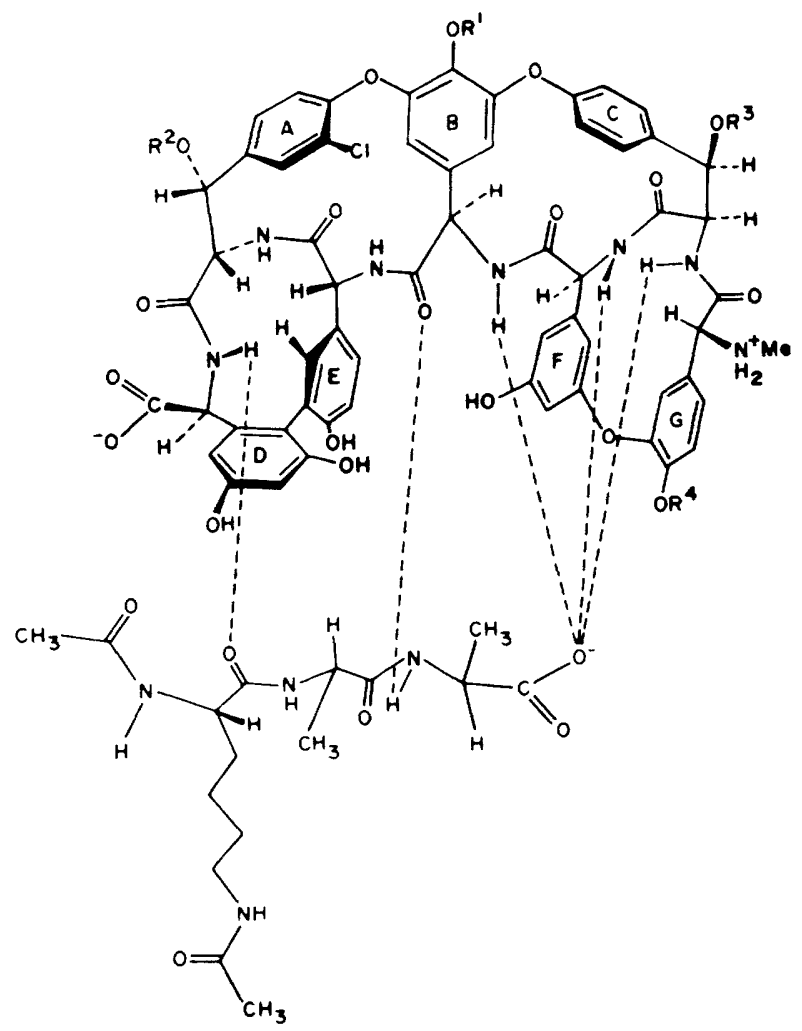

Fig. 4. Diagrammatic representation of the interactions between a peptide terminating in D-alanyl-D-alanine and the aglycone of a glycopeptide : five hydrogen bonds are formed. the vital transpeptidation reaction that links the growing peptidoglycan chain to the mature cell wall. As the result of the inhibition of these two sequential reactions wall, synthesis is frozen.

\section{Resistance to glycopeptides}

The structure of glycopeptides, as well as their unique mechanism of action, is likely to ensure that any resistance mechanism acquired by a bacterium will be unusual compared to conventional mechanisms such as destruction or inactivation of an antibiotic or drastic modification of the target site. Other possible resistance mechanisms include sequestration of the antibiotic molecule by non-specific binding and altered accessibility of the target site. Some bacteria are naturally insensitive to glycopeptides, either because entry through the outer membrane is prevented (gram-negative bacteria) or for an unknown reason (some lactobacilli, leuconostocs, pediococci), though inactivation of the antibiotic molecule has not yet been detected in any instance of resistance. ${ }^{110}$

Sequestration of the available glycopeptide as the result of non-specific binding is also unlikely for various reasons: vast over-production of suitable peptides to complex with the antibiotic molecules would be necessary to raise the MIC of a sensitive strain so dramatically. Such an increase in non-specific binding could occur through secretion of wall precursors into the medium, an enhanced rate of wall turnover involving loss of material into the medium, a substantial increase in the amount of wall peptidoglycan present (and consequent wall thickening) or a decrease in degree of cross-linking in the peptidoglycan with resultant increase in specific binding to non-essential target sites. As yet, none of these scenarios has been detected in investigations of resistant coagulase-negative staphylococci or other resistant (or insensitive) strains $;{ }^{109}$ if any of these situations arose there would be a dramatic decrease in the amount of free glycopeptide in the culture medium of resistant strains in comparison with that of their isogenic sensitive strains and no gross increase in glycopeptide binding to resistant

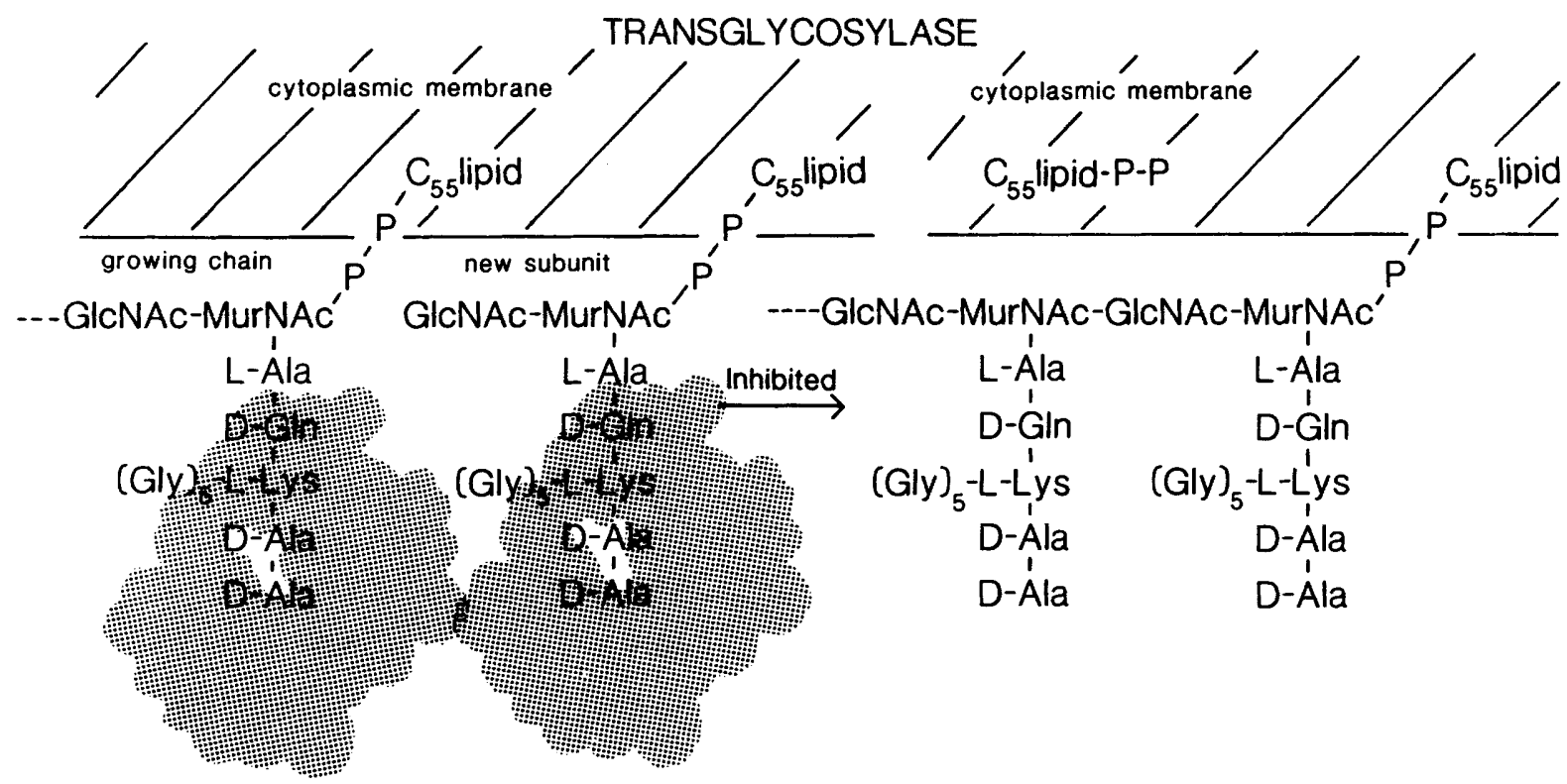

Fig. 5. Diagrammatic representation of glycopeptide molecules bound to D-alanyl-D-alanine sequences in a new wall subunit and the growing nascent glycan chain; these molecules may prevent, by steric hindrance, the transglycosylase reaction that links the nascent chain to the new subunit. The shaded area represents the approximate extent of the glycopeptide. The transglycosylase enzyme is not directly inhibited so resistance cannot result from mutation of the gene encoding the enzyme. Prevention of binding of glycopeptide molecules to the target acylD-alanyl-D-alanine grouping could be brought about by inactivation of glycopeptides (not detected); sequestration of antibiotic in the growth medium (not detected); enzymic modification of the target site (difficult for the subsequent essential transpeptidation reaction to occur); or protection of the target site by another molecule (i.e., changing the accessibility to glycopeptides). 
bacteria or in complex formation in the culture medium has yet been reported.

\section{Genetic studies}

The recently reported resistance in coagulase-negative staphylococci and in enterococci is likely to result either from a change in accessibility of the target or from modification of the target. The resistant enterococci have been studied intensively in several laboratories and at least two types have been identified (table V): high-level resistant strains are resistant to both vancomycin and teicoplanin whereas low-level resistant strains are initially susceptible to teicoplanin and moderately resistant to vancomycin. ${ }^{11-115}$

Resistance is inducible by vancomycin and teicoplanin in the high-level resistant isolates, but only by vancomycin in the low-level resistant strains; however, once resistance to vancomycin is induced, these strains become resistant to teicoplanin as well suggesting that a common factor is involved. The two types of strains differ also with respect to the transferability of resistance to other related or unrelated bacteria. Plasmids encoding resistance have been detected and isolated from some but not all the high-level resistant enterococci ${ }^{116}$ and have been transferred by conjugation to glycopeptide-sensitive strains of the same or related species. In one instance, a plasmid has been transferred from its host of Enterococcus faecium to a range of other gram-positive bacteria including Streptococcus sanguis, Str. lactis, Str. pyogenes and Listeria monocytogenes but not to Staphylococcus aureus or Bacillus subtilis: $:^{114}$ if transfer to, and expression of, glycopeptide resistance in $S$. aureus had been achieved, clinical microbiologists would have been very concerned at the prospect of glycopeptide resistance being added to the growing list of antibiotic resistances in multiresistant strains of staphylococci.

Purified plasmid DNA from resistant $E$. faecium has been used to transform Str. sanguis Challis to glycopeptide resistance; subsequently a 4-K $\mathrm{b} E c o \mathrm{R} 1$ fragment containing the gene (vanA) encoding resistance was cloned in Escherichia coli on a conjugative gram-negative-gram-positive shuttle vector and transferred by conjugation of Ent.faecalis and $B$. thuringiensis, which became resistant to glycopeptides. ${ }^{117}$
Transferable resistance in high-level resistant strains is not always associated with plasmid DNA; plasmids were not detected in either the donor or transconjugants in one report of transfer, and in another a strain cured of glycopeptide resistance retained all three plasmids present in the resistant parent. ${ }^{116}$ It has been suggested that, in these instances, the resistance gene may have a chromosomal location, possibly in association with a transposon. Such a location has also been postulated for the gene encoding resistance in low-level glycopeptide-resistant strains because resistance is not transferable and no plasmids have been detected. Sequencing of the N-terminus of the VANA protein which is present in high-level resistant strains that have been induced (see below) has enabled the van $A$ gene to be identified and sequenced. ${ }^{118}$ The deduced amino-acid sequence corresponded to a protein of calculated $\mathrm{Mr} \mathrm{37.4 \times}$ $10^{3}$, similar to that of the protein seen by sodium dodecyl sulphate (SDS)-polyacrylamide gel electrophoresis $(39 \mathrm{Kda})$. The protein encoded by the van $A$ gene appears to be structurally related to the D-alanyl-D-alanine ligases of $E$. coli and Salmonella typhimurium (28\% and $36 \%$ amino acid identity respectively). Furthermore, the $\operatorname{van} A$ gene, when introduced into an $E$. coli mutant strain with a thermosensitive D-ala-D-ala ligase, was able to achieve complementation at $42^{\circ} \mathrm{C} .{ }^{118}$

\section{Biochemical studies}

The presence of the van $A$ gene in high-level glycopeptideresistant strains and its introduction into sensitive strains is associated with the production of a membrane-associated protein of approximately $39 \mathrm{Kda}$ following induction with glycopeptides. ${ }^{112,119,120}$ The amounts of the protein in sensitive strains or in uninduced resistant bacteria are very low or non-existent. All high-level resistant enterococcal strains that have been examined contain the van $A$ gene as demonstrated by probing with a 290 -bp probe specific for vanA, whereas DNA from the low-level resistant strains did not hybridise with this probe. ${ }^{121}$ Also, hybridisation was not detected with DNA of the teicoplanin-resistant coagulase-negative staphylococci or the intrinsically resistant leuconostocs, pediococci and lacotobacilli. ${ }^{121}$ The presence

Table V. Characteristics of glycopeptide-resistant gram-positive bacteria

\begin{tabular}{|c|c|c|c|c|}
\hline \multirow{3}{*}{$\begin{array}{l}\text { Resistance } \\
\text { property }\end{array}$} & \multicolumn{3}{|c|}{ Acquired resistance in } & \multirow{3}{*}{$\begin{array}{c}\text { Intrinsic resistance* } \\
\text { (Lactobacilli, leuconostocs, } \\
\text { pediococci) }\end{array}$} \\
\hline & \multicolumn{2}{|c|}{ enterococci } & \multirow{2}{*}{ staphylococci } & \\
\hline & High level & Low-level & & \\
\hline \multicolumn{5}{|l|}{$\mathrm{MIC}(\mathrm{mg} / \mathrm{L})$} \\
\hline vancomycin & $\geq 64$ & $16-32$ & $1-2(S)$ & $\geq 1000$ \\
\hline teicoplanin & $\geq 16$ & $0.5(\mathrm{~S})$ & $8-32$ & $\geq 250$ \\
\hline Transferability & + & - & - & - \\
\hline Plasmid-mediated & $+($ some $)$ & - & - & - \\
\hline \multicolumn{5}{|l|}{ Inducibility by } \\
\hline vancomycin & + & + & - & Constitutive \\
\hline teicoplanin & + & - & Constitutive & Constitutive \\
\hline $\begin{array}{l}\text { Mass of resistance protein } \\
\text { (Kda) }\end{array}$ & 39 & $39 \cdot 5$ & ND $†$ & ND \\
\hline Hybridisation to vanA & & & & \\
\hline probe & + & - & - & - \\
\hline \multicolumn{5}{|l|}{ Reaction with antibody to } \\
\hline 39-3-Kda protein & - & + & - & - \\
\hline
\end{tabular}

(S), sensitive.

ND, not determined.

* This group includes the two glycopeptide-producing strains Actinomyces orientalis ATCC 19795 (vancomycin) and A. teichomyceticus ATCC 31211

$\dagger$ Teicoplanin-resistant strains of $S$. epidermidis contain an additional membrane protein (39 Kda) in comparison with a non-isogenic sensitive strain 
of the 39-Kda protein in high-level resistant strains only has been confirmed by immunoblotting with an antibody raised against the purified protein. ${ }^{122}$ Low-level resistant strains also synthesise an inducible membrane protein of similar molecular mass $(39.5 \mathrm{Kda})$ which appears to perform a similar function in conferring resistance $;{ }^{113}$ although the gene encoding it (designated vanB has not yet been sequenced, the $\mathrm{N}$-terminal sequence of the protein was different from that of the $39-\mathrm{Kda}$ protein, and antibodies against the purified protein did not cross-react with the "resistance" protein from high-level resistant strains. ${ }^{119} \mathrm{~A}$ summary of the characteristics of glycopeptide-resistant organisms is given in table $\mathrm{V}$.

\section{Mechanism of resistance- hypotheses}

The balance of evidence suggests that resistance in the enterococci results from altered accessibility of glycopeptide molecules to their target sites. A reduction in accessibility could be due either to production of the target cell-wall peptides (acyl-D-ala-D-ala) by another molecule so that glycopeptide molecules are prevented from binding, or to enzymic modification of the target so that glycopeptides no longer recognise the target and cannot bind to it (or bind with much lower affinity).

Modification of target. The product of the vanA gene has considerable homology with D-ala-D-ala ligases from gramnegative organisms. The specificity of these enzymes is not absolute and, with appropriate substrate pressure, it is conceivable that a wall precursor could be synthesised in which the terminal D-ala-D-ala was replaced with a different dipeptide. ${ }^{121}$ Theoretical considerations render this suggestion unlikely: the introduction of cross-bridges between peptides in the peptidoglycan depends on transpeptidation, which in turn requires the two C-terminal amino acids of the wall precursor to be in the D-configuration. Even if one or both amino acids could be altered to other D-amino acids under normal physiological conditions, it is doubtful if the binding affinity of glycopeptides to the peptide would be changed substantially.

Strong experimental evidence for a different type of modification comes from investigations in which it was shown that wall-membrane fragments of both high-and lowlevel resistant enterococci prevented the binding of vancomycin and teicoplanin to a soluble pentapeptide terminating in acyl-D-ala-D-ala. ${ }^{123}$ In the absence of the wall-membrane fragments, or with an identical preparation from sensitive or uninduced resistant enterococci, binding of vancomycin to the added peptide was not prevented. This is an excellent model system for studying the binding of glycopeptides to their target sites and it was shown that prevention of binding was time dependent; it could be blocked by adding a large excess of the dipeptide D-ala-D-ala (which does not itself bind to glycopeptides), and it was destroyed by heating the wall-membrane preparation-these observations are consistent with the involvement of an enzyme in the protection phenomenon. ${ }^{123}$ Furthermore, in these experiments there was a high molar excess of pentapeptide to induced $39-\mathrm{Kda}$ protein which rules out simple binding as a resistance mechanism. It was postulated that enzymic modification may have involved the release of $D$-alanine from the pentapeptide, ${ }^{123}$ though such an activity would prevent subsequent transpeptidation if it occurred in vivo. There are two lines of evidence not in accord with this hypothesis: the resistant enterococci are susceptible to some derivatives of vancomycin, ${ }^{122}$ suggesting that the binding site for glycopeptides has not been changed substantially, and, more significantly, treatment of the wall-membrane preparation of the resistant enterococci with SDS at $100^{\circ} \mathrm{C}$ permitted binding of vancomycin to the residual wall whereas no binding occurred to the native preparation. ${ }^{123}$ This suggests that no drastic modification of the glycopeptide binding site has occurred.

Protection of target. Two lines of evidence suggest that the additional membrane protein present in resistant strains of enterococci that have been induced with glycopeptides recognises $D$-ala-D-ala, the binding site of glycopeptides. The VANA protein has considerable homology with D-ala$D$-ala ligases ${ }^{118}$ (as discussed above) and the prevention of binding of vancomycin to a synthetic pentapeptide terminating in D-ala-D-ala by a wall-membrane preparation containing either the $38-\mathrm{Kda}$ or the $39 \cdot 5-\mathrm{Kda}$ protein was eliminated by an excess of D-ala-D-ala. ${ }^{123}$ However, simple binding of the additional membrane protein to the glycopeptide binding sites is unlikely in view of the large number of these sites $\left(2 \times 10^{7}\right.$ in a staphylococcus), unless the topographical distribution of the protein in the membrane protects the wall precursors as they are extruded through the membrane and until they are fully incorporated into the mature wall.

\section{Glycopeptide resistance in coagulase-negative staphylococci}

The degree of resistance to glycopeptides in coagulasenegative staphylococci, particularly $S$. epidermidis and $S$. haemolyticus, is not as great as with the enterococci. Furthermore, these isolates are resistant to teicoplanin but not to vancomycin. ${ }^{124}$ This implies that the resistance mechanism will be different from that in the enterococci and could be accounted for by slightly altered accessibility. An additional membrane protein of $39 \mathrm{Kda}$ has been found in resistant isolates of $S$. epidermidis in comparison with sensitive isolates (non-isogenic) but there is no direct evidence that this protein is involved with resistance except by analogy with the enterococci (M. D. O'Hare and P. E. Reynolds, unpublished observations).

\section{Summary}

Selective antibiotic pressure due to the increased use of glycopeptide antibiotics for the control of infections caused by gram-positive bacteria has resulted in the emergence of resistance in enterococci and coagulase-negative staphylococci. It is of particular concern that resistance is mediated in some enterococcal strains by self-transferable plasmids with a wide hose range; such a situation may lead to the transfer of this type of glycopeptide resistance to other grampositive pathogens. ${ }^{121}$

Although glycopeptide antibiotics have been used for 30 years, cases of resistance have been slow to emerge. This is probably due to the unique interaction between a compact and relatively rigid antibiotic molecule and its target, which is, unusually, a substrate for peptidoglycan synthesis rather than an enzyme involved in catalysis. For this reason, any mechanism of resistance is likely to be unusual: diminished accessibility of glycopeptides to their target sites is the most likely possibility in both enterococci and coagulase-negative staphylococci but whether this results from target protection or modification has not yet been demonstrated convincingly.

\section{SURVEILLANCE OF ANTIBIOTIC RESISTANCE IN} ENGLAND AND WALES

\section{R. C. George, P. B. Norbury and Dorothy James}

Antibiotic Reference Laboratory, Division of Hospital Infection, Central Public Health Laboratory, 61 Colindale Avenue, London NW9 SHT

Surveillance of antibiotic resistance may be done at both local and national levels. At local level, the compilation of 
results of routine diagnostic work for surveillance purposes is readily achieved, particularly if the work of the laboratory is computerised. ${ }^{125,126}$ The data derived may be used in the formulation of local prescribed guidelines and policies. ${ }^{127,128}$ Special studies and surveys are also undertaken at local level and may involve additional susceptibility testing and investigation of the mechanisms and genetics of particular resistance markers detected. Such studies may relate to local experience with particular pathogens, e.g., enterococci in Nottingham, ${ }^{129}$ or cover prolonged periods of study for organisms isolated from particular sites of infection, such as blood, e.g., Phillips and co-workers reported recently on the antibiotic susceptibility of bacteraemia at St Thomas' Hospital over a 20 -year period. ${ }^{127}$

For the definition of national trends in antibiotic resistance, cultures isolated in different laboratories may be referred to one centre, where they can be examined for antibiotic susceptibility with standardised methods. Such studies may be specifically organised for this purpose ${ }^{130,131}$ or result from the examination of cultures submitted to reference laboratories for typing or other specialised studies. $^{132,133}$ The number of different cultures, participating centres, and time periods of study that may be included in specially organised surveys are necessarily restricted by resource and staffing implications. Similarly, data derived from reference laboratory studies may be biased because the criteria for submission of status for reference work are not standardised.

An alternative approach to national surveillance is provided by the referral of results of susceptibility tests (done for diagnostic and therapeutic purposes) from diagnostic laboratories to one or more centres where they are compiled and analysed. Large multi-centre studies spanning several years have been performed in the USA ${ }^{134}$ and the UK. ${ }^{135}$ The recent UK report by Spencer and co-workers utilised a computer-based reporting scheme called Microbase ${ }^{136}$ to collect susceptibility data on nearly 367000 isolates from 61 medical microbiology laboratories distributed throughout much of the UK. ${ }^{135}$

The remainder of this paper describes an approach to the continuous surveillance of antibiotic resistance which utilises and expands the existing scheme for reporting bacterial isolates from cases of bacteraemia and meningitis to the PHLS Communicable Disease Surveillance Centre (CDSC).

The CDSC operates a voluntary, confidential, laboratory reporting scheme for a wide range of infections in England and Wales. Within the CDSC reporting scheme, laboratories are requested to report significant bacterial isolates from cases of bacteraemia and meningitis. During 1988, a major re-organisation of this reporting scheme was initiated involving the introduction of new computers, software and report forms. This re-organisation suggested to staff within the Division of Hospital Infection (DHI) of the Central Public Health Laboratory (CPHL) an opportunity to undertake continuous surveillance of antimicrobial susceptibility data for bacteraemia and meningitis isolates reported to CDSC. Accordingly, after consultation with colleagues in $\mathrm{CDSC}$, the new Communicable Disease Report (CDR) Form 2 was modified to include a request to the reporting laboratories to list the antimicrobial susceptibility test results obtained from routine diagnostic work on the cultures being reported. This approach has several advantages. Firstly, the data collected relates to organisms judged responsible for significant infection. Secondly, the only additional workload required in the reporting laboratory is to add their own susceptibility test results to the form they are already completing. Thirdly, the majority of all diagnostic microbiology laboratories in England and Wales participate in the reporting scheme giving very wide coverage. Fourthly, the results obtained can be analysed geographically and by clinical and epidemiological features (where these data are available); and finally the surveillance scheme can run continuously over many years providing a unique database providing trends in antibiotic resistance. The new report forms, with the request to include susceptibility test results, were introduced at the beginning of 1989. This paper presents some of the results obtained for bacterial isolates reported during the first half of the 1989.

Reporters were asked to enter antibiotic susceptibility test results as susceptible, intermediate or resistant (using their own definitions), for the bacterial isolates they were reporting. The susceptibility test results were added to the existing CDSC computer database records of individual patient infections (containing details of the source laboratory, and clinical and epidemiological features) by staff of the Division of Hospital Infection. As only those agents to which clinical isolates were routinely tested in the individual laboratories were included in the reports, there was considerable variation in the total number of tests for each antibiotic. Generally, we have selected for inclusion those antibiotics for which a result appears in $\geqslant 40-50 \%$ of reports for a particular species. When positive isolation was reported from both blood and CSF in cases of meningitis, infection was counted only once. Therefore each organism included in these totals relates to an individual patient's infection.

In this preliminary report it is not feasible to present the wealth of data that is being generated by this surveillance system. Therefore, we have chosen for inclusion data relating to four pathogens commonly reported to CDSC as causing bacteraemia or meningitis, or both. Tables VI-IX show the reported susceptibility test results for Escherichia coli, Staphylococcus aureus, Streptococcus pneumoniae and Pseudomonas aeruginosa. The number of different laboratories from which the reports were received is also shown. In reports of these four bacterial infections, $84-87 \%$ included results of antimicrobial susceptibility tests and $87-92 \%$ of individual reporting laboratories included such data in their reports.

For those agents most likely to be used therapeutically for $E$. coli bacteraemia (table VI)-the cephalosporins and aminoglycosides-full susceptibility was reported for $>98 \%$ of isolates with the exception of cefuroxime, for which full susceptibility was reported for $92.6 \%$. Susceptibility to ampicillin or amoxycillin was reported for $45 \%$ and susceptibility to trimethoprim for $80 \%$ of the isolates tested.

Amongst the $2366 \mathrm{~S}$. aureus bacteraemias reported from 249 laboratories, susceptibility test results were included for $87 \%$ (table VII). Apart from the $85 \%$ of isolates resistant to penicillin, little antibiotic resistance was reported for the agents tested, with $92 \%$ sensitivity to erythromycin, $98 \%$ to methicillin, and $97 \%$ to gentamicin and fusidic acid.

The pneumococcus was the third most common organism reported. Of these reports, $85 \%$ included susceptibility test results. Full susceptibility to penicillin was reported for almost all; with only three of 1701 isolates were reported to be resistant or of intermediate sensitivity to penicillin. Of nearly 1600 isolates for which reports included details of erythromycin susceptibility, $2.5 \%$ were reported as resistant or of intermediate susceptibility. Nearly $99 \%$ of the 385 isolates for which chloramphenicol susceptibility was reported were recorded as sensitive. This total includes virtually all those from meningitis but relatively few of those from bacteraemia.

Susceptibility test results were received for $86 \%$ of 499 cases of bacteraemia due to Pseudomonas aeruginosa reported from 184 laboratories (table IX). Susceptibility to gentamicin was noted in $91 \%$ of 338 reports, $1.5 \%$ were reported to be of intermediate susceptibility and $7.4 \%$ resistant to gentamicin. Susceptibility to ciprofloxacin, ceftazidime, piperacillin and azlocillin was reported for $95 \%, 94 \%, 95 \%$ and $90 \%$ of isolates respectively amongst reports that included results for these antibiotics. 
The results obtained to date and the continuing support that the surveillance scheme is receiving from microbiologists in England and Wales suggest that this approach to surveillance is likely to be useful and relevent for the foreseeable future. It should be possible to monitor and report trends and shifts in antibiotic susceptibility for a wide range of common pathogens causing bacteraemia and meningitis.

The accuracy of results reported in such a surveillance study could be questioned. However, the results received are those generated during normal laboratory testing for diagnostic and therapeutic purposes. Such tests are subject to both internal and external quality control. Results from the National External Quality Assurance Scheme for micro- biology show that, for most organism and antibiotic combinations examined within the scheme, agreement with the designated correct result is achieved on $80-100 \%$ of occasions, (Personal Communication, J.J.S. Snell). Thus, it seems reasonable to accept the reported results as valid.

For $E$. coli, the results obtained for gentamacin susceptibility are identical to those obtained in the 3-year survey reported by Spencer ${ }^{135}-1 \%$ resistance - and very similar to the $1.6 \%$ gentamicin resistance amongst 371 blood-culture isolates reported from the Bristol survey in $1986 .{ }^{131}$ The latter two studies reported $97 \%$ and $98 \%$ of $E$. coli strains to be sensitive to cefuroxime, compared with the $92.6 \%$ reported here. It remains to be seen whether there is any significant trend towards resistance to cefuroxime in isolates

Table VI. Antimicrobial susceptibility of $E$. coli isolates from cases of bacteraemia reported to CDSC/DHI from England and Wales, Jan.-June 1989

\begin{tabular}{|c|c|c|c|c|}
\hline \multirow{2}{*}{ Antibiotic } & \multirow{2}{*}{$\begin{array}{c}\text { Number }(\%) \\
\text { tested }\end{array}$} & \multicolumn{3}{|c|}{ Number $(\%)$ of strains that were } \\
\hline & & $\mathbf{S}$ & I & $\mathbf{R}$ \\
\hline $\begin{array}{l}\text { Ampicillin/Amoxycillin } \\
\text { Cefotaxime } \\
\text { Ceftazidime } \\
\text { Cefuroxime } \\
\text { Ciprofloxacin } \\
\text { Gentamicin } \\
\text { Trimethoprim }\end{array}$ & $\begin{array}{l}3070(97 \cdot 5) \\
1554(49 \cdot 4) \\
1046(33 \cdot 2) \\
2189(69 \cdot 6) \\
1572(50) \\
3015(95 \cdot 8) \\
2261(71 \cdot 8)\end{array}$ & $\begin{array}{l}1400(45 \cdot 6) \\
1542(99 \cdot 2) \\
1036(99 \cdot 0) \\
2027(92 \cdot 6) \\
1568(99 \cdot 7) \\
2958(98 \cdot 1) \\
1816(80 \cdot 3)\end{array}$ & $\begin{array}{r}119(3 \cdot 9) \\
3(0 \cdot 2) \\
4(0 \cdot 4) \\
72(3 \cdot 3) \\
3(0 \cdot 2) \\
27(0 \cdot 9) \\
19(0 \cdot 8)\end{array}$ & $\begin{array}{c}1551(50 \cdot 5) \\
9(0 \cdot 6) \\
6(0 \cdot 6) \\
90(4 \cdot 1) \\
1(0 \cdot 1) \\
80(1 \cdot 0) \\
426(18 \cdot 8)\end{array}$ \\
\hline \multicolumn{3}{|c|}{$\begin{array}{l}\text { Total number reported } \\
\text { Number of reporting laboratories } \\
\text { Number }(\%) \text { with one or more sensitivity results } \\
\text { Number }(\%) \text { of laboratories reporting sensitivity results } \\
S \text {, sensitive; I, intermediate sensitivity; } R \text {, resistant. }\end{array}$} & \multicolumn{2}{|r|}{$\begin{array}{l}3586 \\
254 \\
3147(87 \cdot 8) \\
237(93 \cdot 3)\end{array}$} \\
\hline
\end{tabular}

Table VII. Antimicrobial susceptibility of $S$. aureus isolates from cases of bacteraemia reported to CDSC/DHI from England and Wales, Jan.-June 1989

\begin{tabular}{|c|c|c|c|c|}
\hline \multirow{2}{*}{ Antibiotic } & \multirow{2}{*}{$\begin{array}{c}\text { Number }(\%) \\
\text { tested }\end{array}$} & \multicolumn{3}{|c|}{ Number $(\%)$ of strains that were } \\
\hline & & $\mathbf{S}$ & I & $\mathbf{R}$ \\
\hline $\begin{array}{l}\text { Penicillin } \\
\text { Erythromycin } \\
\text { Methicillin } \\
\text { Gentamicin } \\
\text { Fusidic acid }\end{array}$ & $\begin{array}{l}1995(96 \cdot 6) \\
1981(95 \cdot 9) \\
1962(95 \cdot 0) \\
1623(78 \cdot 6) \\
1659(80 \cdot 3)\end{array}$ & $\begin{array}{l}292(14 \cdot 6) \\
1830(92 \cdot 4) \\
1920(97 \cdot 9) \\
1571(98 \cdot 8) \\
1618(97 \cdot 5)\end{array}$ & $\begin{array}{l}4(0 \cdot 2) \\
10 \cdot 9(0 \cdot 9) \\
5(0 \cdot 3)\end{array}$ & $\begin{array}{l}1703(85 \cdot 4) \\
147(7 \cdot 4) \\
42(2 \cdot 1) \\
38(2 \cdot 3) \\
36(2 \cdot 2)\end{array}$ \\
\hline \multicolumn{3}{|c|}{$\begin{array}{l}\text { Total number reported } \\
\text { Number of reporting laboratories } \\
\text { Number }(\%) \text { with one or more sensitivity results } \\
\text { Number }(\%) \text { of laboratories reporting sensitivity results }\end{array}$} & \multicolumn{2}{|r|}{$\begin{array}{l}2366 \\
249 \\
2065(87 \cdot 3) \\
237(92 \cdot 0)\end{array}$} \\
\hline
\end{tabular}

Table VIII. Antimicrobial susceptibility of pneumococci isolated from cases of bacteraemia and meningitis reported to CDSC/DHI from England and Wales, Jan.-June 1989

\begin{tabular}{|c|c|c|c|c|}
\hline \multirow{2}{*}{ Antibiotic } & \multirow{2}{*}{$\begin{array}{c}\text { Number }(\%) \\
\text { tested }\end{array}$} & \multicolumn{3}{|c|}{ Number $(\%)$ of strains that were } \\
\hline & & $\mathbf{S}$ & I & $\mathbf{R}$ \\
\hline $\begin{array}{l}\text { Penicillin } \\
\text { Tetracycline } \\
\text { Erythromycin } \\
\text { Chloramphenicol }\end{array}$ & $\begin{array}{r}1701(98 \cdot 5) \\
756(43 \cdot 8) \\
1596(92 \cdot 4) \\
385(22 \cdot 3)\end{array}$ & $\begin{array}{r}1698(99 \cdot 8) \\
735(97 \cdot 2) \\
1551(97 \cdot 2) \\
380(98 \cdot 7)\end{array}$ & $\begin{array}{l}2(0 \cdot 1) \\
9(1 \cdot 2) \\
4(0 \cdot 3) \\
1(0 \cdot 3)\end{array}$ & $\begin{array}{r}1(0 \cdot 06) \\
12(1 \cdot 6) \\
41(2 \cdot 5) \\
4(1 \cdot 0)\end{array}$ \\
\hline \multicolumn{3}{|c|}{$\begin{array}{l}\text { Total number reported } \\
\text { Number of reporting laboratories } \\
\text { Number }(\%) \text { with one or more sensitivity results } \\
\text { Number }(\%) \text { of laboratories reporting sensitivity results }\end{array}$} & \multicolumn{2}{|c|}{$\begin{array}{r}2040 \\
244 \\
1728(84 \cdot 7) \\
229(93 \cdot 6)\end{array}$} \\
\hline
\end{tabular}


Table IX. Antimicrobial susceptibility of $P$. Aeuruginosa isolates from cases of bacteraemia reported to CDSC/DHI from England and Wales, Jan.-June 1989

\begin{tabular}{|c|c|c|c|c|}
\hline \multirow{2}{*}{ Antibiotic } & \multirow{2}{*}{$\begin{array}{c}\text { Number }(\%) \\
\text { tested }\end{array}$} & \multicolumn{3}{|c|}{ Number $(\%)$ of strains that were } \\
\hline & & $\mathbf{S}$ & I & $\mathbf{R}$ \\
\hline $\begin{array}{l}\text { Azlocillin } \\
\text { Ceftazidime } \\
\text { Ciprofloxacin } \\
\text { Gentamicin } \\
\text { Piperacillin }\end{array}$ & $\begin{array}{l}174(49 \cdot 6) \\
247(70 \cdot 4) \\
288(82 \cdot 1) \\
338(96 \cdot 3) \\
169(48 \cdot 1)\end{array}$ & $\begin{array}{l}156(89 \cdot 7) \\
233(94 \cdot 3) \\
275(95 \cdot 5) \\
308(91 \cdot 1) \\
160(94 \cdot 7)\end{array}$ & $\begin{array}{l}6(3 \cdot 4) \\
3(1 \cdot 2) \\
7(2 \cdot 4) \\
5(1 \cdot 5) \\
3(1 \cdot 8)\end{array}$ & $\begin{array}{r}12(6 \cdot 9) \\
11(4 \cdot 5) \\
6(2 \cdot 1) \\
25(7 \cdot 4) \\
6(3.6)\end{array}$ \\
\hline \multicolumn{4}{|c|}{$\begin{array}{l}\text { Total number reported } \\
\text { Number of reporting laboratories } \\
\text { Number }(\%) \text { with one or more sensitivity results } \\
\text { Number }(\%) \text { of laboratories reporting sensitivity results }\end{array}$} & $\begin{array}{l}409 \\
184 \\
351(85 \cdot 8) \\
160(87 \cdot 0)\end{array}$ \\
\hline
\end{tabular}

of $E$. coli from bacteraemia. The presence in these data of a small number of reports of resistance or intermediate sensitivity to cefotaxime and ceftazidime at $0.8 \%$ and $1 \%$, respectively, of isolates tested against these antibiotics is suggestive of emerging resistance to these agents. As this survey continues it should be possible to plot any such changes in susceptibility to cephalosporins and, indeed, to other antimicrobial agents over time.

Amongst the isolates of $S$. aureus from bacteraemia, susceptibility to gentamicin and methicillin was reported in $97 \%$ and $98 \%$ respectively. These results are similar to the $98 \%$ sensitivity to gentamicin for 204 blood-cultures isolates of $S$. aureus reported in Bristol ${ }^{131}$ and the $98 \%$ sensitivity to methicillin reported for Spencer. ${ }^{135}$

Amongst pneumococci, very low levels of resistance to penicillin and chloramphenicol were reported. However, it should be noted that strains resistant to these agents are responsible for significant infections in patients in England and Wales, albeit in very low numbers. Resistance to erythromycin was noted in $2.5 \%$ of nearly 1600 reports of isolates from blood or CSF, compared with the $1 \%$ of $>7000$ pneumococci from various clinical sources reported by Spencer. ${ }^{135}$ Whether this small difference represents a change in overall susceptibility to erythromycin may become apparent as the survey continues.

The $7.4 \%$ incidence of resistance to gentamicin amongst 338 bacteraemia isolates of $\boldsymbol{P}$. aeruginosa is notably higher than the $1 \%$ resistance reported for Pseudomonas spp. ${ }^{135}$ and a little higher than the $4 \%$ resistance reported for 23 blood isolates in Bristol. ${ }^{131}$ A survey of 1866 isolates of $P$. aeruginosa collected from 24 British hospitals noted resistance in $5.5 \%{ }^{137}$

With a few exceptions the results reported here present a reasonably reassuring picture of continued bacterial susceptibility to a wide range of antibiotics. Comparison of these results with those obtained from culture-based surveys shows reasonable concordance. The continuous surveillance of the antibiotic susceptibility of bacteraemia isolates by the present system, supplemented with occasional culturebased surveys of particular species to define precisely the genetics and mechanisms of resistance, offer a simple and cost effective approach to national surveillance.

IS THERE ANY RELATIONSHIP BETWEEN BACTERIAL RESISTANCE AND VIRULENCE?

L. Gutmann and G.S. Tillotson*

Service de Microbiologie, Hôpital St Joseph, Paris Cedex 14, France, and *Research and Development Department, Bayer (UK) Ltd, Newbury, Berkshire, RG13 IJA

To access the association between virulence and antibiotic resistance, it is essential to examine the interaction from two aspects - firstly, in relation to plasmid encoded resistance and secondly for chromosomally mediated resistance and virulence; the interplay may be demonstrated by the use of appropriate animal models. Many questions on this topic have been raised and a multitude remain unsolved. For an organism to be virulent it must possess some features or factors which may include: (i) the ability to adhere to other cells (via pili, fimbriae or adhesins); (ii) the production of an extracellular toxin; or (iii) the ability to penetrate the tissues or cells by virulence factors (once inside the cell the bacteria may multiply and destroy it). Several of these features are exquisitely plasmid mediated, others are only chromosomal.

Many virulence or pathogenicity factors are known to be encoded by plasmids. Some are toxins that cause diarrhoea; some are factors responsible for the adhesion of bacteria to other cells; some are components that allow bacteria to penetrate HeLa cells and then multiply; and some are features that enable salmonellae to persist in various organs. Many of these virulence factors happen to be associated with antibiotic resistance markers carried on plasmids. One of the best known instances of a linkage between resistance and virulence conferred by a plasmid is that of enterotoxin production amongst antibiotic-resistant Escherichia coli isolates in the Far East. ${ }^{138}$ Toxigenic $E$. coli produce either a heat-labile, antigenic, large-molecular-weight toxin (LT) or a heat-stable, non-antigenic toxin (ST), or both. These $E$. coli strains contain plasmids that carry the genetic information necessary for the production of these toxins. Several conflicting reports suggested that $E$. coli may or may not be able to carry together plasmids conferring enterotoxin production and antibiotic resistance, but Echeverria et al. collected 176 enterotoxigenic $E$. coli (ETEC) strains for the Far East, of which $72 \%$ were resistant to one or more antibiotic; $44 \%$ were resistant to four or more agents. In transfer experiments, $80 \%$ of 31 ETEC strains transferred part of their resistance pattern and $35 \%$ also transferred their toxigenicity profile. None of the recipients acquired toxigenicity without antibiotic resistance. These workers concluded that ETEC isolated from the Far East in 1978 were frequently resistant to antimicrobial agents, and that genes coding for resistance and enterotoxin production could be transferred together in vivo. It was not known if this phenomenon could occur in the human gastrointestinal tract.

This type of association has also been observed by other workers. Wachsmuth et al. ${ }^{139}$ found that $36 \%$ of a multiresistant $E$. coli population produced ST and that all toxigenic strains were resistant to antibiotics. Smith and Linggood $^{140}$ examined ETEC isolates from pigs and found that toxin-conferring plasmids were transmitted with resistance plasmids and, although not linked, the plasmids were transferred together. Because interbacterial transfer of antibiotic resistance occurs more efficiently in animals when 
antimicrobial agents are used, caution was advocated against "the widespread use of antibiotics because it might result in an increased incidence of bacteria possessing pathogenic plasmids in the environment of man and domestic animals".

The precise mechanisms of virulence of enteropathogenic E. coli (EPEC) are not known. However, work by Laporta et al. ${ }^{141}$ has shown that EPEC adhere to HeLa cells in two different ways. These are termed localised adherence (LA) and diffuse adherence (DA). The bacteria demonstrating LA stick to localised areas of the cells in which they form distinct microcolonies or clusters, whereas the isolates showing DA adhere to the whole surface of the HeLa cells. The LA characteristic has been shown to be consistent in EPEC serotypes and focal adherence of $E$. coli $\mathrm{O} 111: \mathrm{H}$ cells to small bowel epithelia and packed aggregates on HEp-2 cells have been described previously by Clausen and Christie. ${ }^{142}$

Laporta et al. ${ }^{142}$ confirmed that naturally occurring plasmids encoding both LA and antibiotic resistance have been recognised in $E$. coli. These workers examined six strains of EPEC possessing transferable drug resistance; two strains possessed the characteristic of joint factor expression. One strain carried two plasmids, one coding for ampicillin (Ap) resistance and the other for LA, whereas the other strain contained only one plasmid coding for resistance to four antibiotics and LA. Curing by acridine orange of an $\mathrm{ApLA}^{+}$transconjugant showed that both features were lost simultaneously.

The situation is different in bacteria possessing chromosomal mutations conferring antibiotic resistance. One of the best known examples of this is an alteration in a porin, a protein component (Omp) of the outer membrane of gramnegative bacteria responsible for the movement into the bacterial cells of many chemicals such as nutrients, ions and certain antibiotics. A very complex control mechanism regulates the quantitative production of porins and affects their sensitivity to different families of antibiotics such as $\beta$ lactams, chloramphenicol, tetracycline and the quinolones. The porins span the outer membrane as protein trimers that admit small hydrophilic molecules to the cytoplasm. In $E$. coli, Omp F has been shown to be larger than Omp C $(1.2 \mathrm{~nm}$ compared with $1 \cdot 1 \mathrm{~nm}$ ). Thus, the ratio of Omp F. Omp C affects the range of chemicals and antibiotics admitted to the cell. Genes coding for the control of Omp F and Omp C are under the transcriptional regulation of the Omp R gene, which itself is part of the component regulatory system Omp $\mathbf{R}$ and env $\mathbf{Z}$. The env $\mathbf{Z}$ gene encodes a transmembrane sensory component which acts as a donor for the product of Omp $\mathrm{R}$, a transcriptional regulator. Dorman et al. ${ }^{143}$ introduced, via transposon-generated mutation, into a mouse-virulent strain of Salmonella typhimurium, various Omp changes, which included Omp C, Omp D (another porin present in salmonellae), Omp F and Omp R. Once characterised, the mutated strains were inoculated into $\mathrm{BALB} / \mathrm{c}$ mice by either the oral or intravenous route. In comparison with the parent strain, Omp C- or Omp Fdeficient strains were identical in virulence. The Omp D mutant was slightly less virulent whereas the mutant Omp $\mathrm{R}$ failed to kill the mice after oral challenge and showed a markedly reduced intravenous LD50. Furthermore, the Omp $\mathrm{R}$ mutants persisted for several weeks in murine tissues, and appeared to protect against subsequent challenge by the parent strain.

Cyclic AMP (cAMP) and the cAMP receptor protein (CRP) are essential for the transcription of many genes and operons involved in catabolite transport and breakdown. The cAMP levels in cells influence various factors related to virulence or pathogenicity, such as synthesis of fimbriae and flagella and manufacture of at least one Omp. Deficiency in cAMP and CRP can also be associated with $\beta$-lactam resistance. Curtis and Kelly ${ }^{144}$ developed strains of Salmon- ella typhimurium which were unable to synthesise adenyl cyclase and CRP and thus were deficient in cAMP. The parent strain of $S$. typhimurium possessed a virulence plasmid, pStSR100, which enabled it to attach to, invade and persist in Peyer's patches but was defective in traversing to the mesenteric lymph nodes and spleen. With several different genotypic mutant derivatives, studies were performed to assess the following properties; carbohydrate, metabolism, flagellum synthesis, colony size, virulence in BALB/c mice, genetic stability, tissue tropism, persistence of avirulent mutants and immunogenicity. All of the mutant strains were less virulent and induced a high level of protective immunity. Tissue tropism and persistence were not markedly different in the cAMP and CRP mutants. However, the genetic mutations created appeared to be stable. The infective dose required for the mutants was significantly higher than that of the parental strain, whereas the colony size and generation times of the mutant strains were smaller and longer than the wild type. Thus, mutations causing loss of adenyl cyclase or loss of CRP lead to avirulent but immunogenic strains of $S$. typhimurium.

Shigella flexneri causes dysentery in man by penetrating and multiplying inside human colonic epithelial cells. This invasive process has been demonstrated in vitro by showing HeLa cell invasion and a subsequent cytopathic effect. The expression of genes located on the chromosome is required for full virulence, but loci encoding for entry into epithelial cells are located on a $220-\mathrm{kb}$ virulence plasmid. Bernadini $e t$ al. ${ }^{145}$ constructed mutants of the Omp B locus which contains the Omp $\mathbf{R}$ and env $\mathbf{Z}$ genes, which in turn are responsible for regulatory changes in accordance with environmental stimuli. Deletion of the Omp B locus via an allelic exchange yielded a mutant that expressed a low level of entry into cells and a limited capacity to survive intracellularly. Other virulence assays confirmed that the virulence of the mutant was severely impaired.

These three examples of chromosomal mutations which were associated with decreased virulence have shown that genetic changes which are known to be related to antibiotic resistance (although it was not tested in these particular mutants) may have a price in terms of viability, persistence and invasiveness. Two examples follow, in which sensitive clinical isolates of bacteria resistant in vitro have been investigated with respect to virulence in a mouse infection model.

Resistance to $\beta$-lactam and aminoglycoside antibiotics in Pseudomonas aeruginosa may be conferred either by enzymes (plasmid or chromosomal) or by a change to permeability. When aminoglycoside resistance is present it may result from either a complete loss or significant reduction of the $\mathrm{O}$ antigenic subunits of lipopolysaccharide. Bryan et al. ${ }^{146}$ examined the virulence of a series of mutant and transductant strains of $P$. aeruginosa that expressed $\beta$-lactamase and aminoglycoside resistance, in a mouse model of peritonitis and septicaemia (table $X$ ). The mechanisms of resistance of these mutant strains included (1) for $\beta$-lactam antibiotics, the production of a constitutive $\beta$-lactamase, a decrease in permeability and a decreased affinity for penicillin-binding proteins, and (2) for aminoglycoside antibiotics, a decrease in cytochrome and nitrate reductase as the absence or reduction in the subunits of LPS. The results for these various mutant strains in the mouse peritonitis model revealed that bacteria showing mechanisms of resistance to $\beta$-lactam antibiotics all retained virulence properties similar to the parent. This is consistent with observations of these isolates that showed no change of morphology, growth rate or production of exotoxin A. However, the aminoglycosideresistant strains showed a significant decrease in virulence. Three strains with altered cytochrome demonstrated slower growth rates and two mutant strains had "uncapped" LPS. Thus, in contrast to strains resistant to $\beta$-lactam agents, 
Table X. Strains, properties and features of $P$. aeruginosa strains ${ }^{146}$

\begin{tabular}{|c|c|c|c|c|c|c|}
\hline \multirow{2}{*}{$\begin{array}{l}\text { Strain } \\
\text { no. }\end{array}$} & \multirow{2}{*}{$\begin{array}{l}\text { Resistance } \\
\text { mechanism }\end{array}$} & \multicolumn{2}{|c|}{$\operatorname{MIC}(\mathrm{mg} / \mathrm{l})$} & \multirow{2}{*}{ Virulence } & \multirow{2}{*}{ LD50 } & \multirow{2}{*}{$\begin{array}{l}\text { Growth } \\
\text { rate }\end{array}$} \\
\hline & & Piperacillin & Gentamicin & & & \\
\hline $\begin{array}{l}\text { PA } 0503 \\
\beta \text {-lactam resistant }\end{array}$ & None & 1 & 1 & - & $7 \times 10^{5}$ & Normal \\
\hline $\begin{array}{l}\text { P-lactam resistant } \\
\text { PCC } 118\end{array}$ & $\begin{array}{l}\text { Constitutive } \beta \text {-lacta- } \\
\text { mase, permeability } \\
\text { decrease to } \beta \text {-lacta- } \\
\text { mase }\end{array}$ & $>120$ & 1 & 一 & $5.5 \times 10^{5}$ & Normal \\
\hline PCC 45 & $\begin{array}{l}\text { Permeability de- } \\
\text { crease }\end{array}$ & 4 & 1 & - & $6 \times 10^{5}$ & Normal \\
\hline $\mathrm{PCC} 17$ & $\begin{array}{l}\text { Decreased affinity to } \\
\text { PBP }\end{array}$ & 80 & 1 & - & $5 \times 10^{5}$ & Normal \\
\hline PCC 2 & $\begin{array}{l}\text { Decreased affinity to } \\
\text { PBP } 3\end{array}$ & 4 & 1 & - & $6 \times 10^{5}$ & Normal \\
\hline \multicolumn{7}{|c|}{ Aminoglycoside resistant } \\
\hline PAO 2401 & $\begin{array}{l}\text { Cytochrome and } \\
\mathrm{NO}_{3} \text { reduction }\end{array}$ & 1 & 15 & $\downarrow$ & $72 \cdot 1 \times 10^{6}$ & $\downarrow$ \\
\hline PAO 2402 & $\begin{array}{l}\text { No cytochrome and } \\
\mathrm{NO}_{3} \text { reduced }\end{array}$ & 1 & 4 & $\downarrow$ & $72 \cdot 1 \times 10^{6}$ & $\downarrow$ \\
\hline PAO 2403 & $\begin{array}{l}\text { No cytochrome and } \\
\mathrm{NO}_{3} \text { reduced }\end{array}$ & 1 & 16 & $\downarrow$ & $72 \cdot 1 \times 10^{6}$ & $\downarrow$ \\
\hline PAO 503-18 & $\begin{array}{l}\text { Absence of LPS sub- } \\
\text { unit }\end{array}$ & 1 & 4 & $\downarrow$ & $72 \cdot 1 \times 10^{6}$ & Normal \\
\hline PAO 503-16 & $\begin{array}{l}\text { Marked reduction in } \\
\text { LPS subunit }\end{array}$ & 1 & 4 & $\downarrow$ & $72 \cdot 1 \times 10^{6}$ & Normal \\
\hline
\end{tabular}

those with reduced aminoglycoside sensitivity manifested reduced virulence. Similar mutant strains have been isolated from cystic fibrosis patients, almost all of whom had repeated intensive courses of aminoglycosides. It is probable that these strains may persist during antibiotic therapy despite their reduced virulence. ${ }^{146}$

A further group of antimicrobial agents is the 4-fluoroquinolones, of which ciprofloxacin is one of the most active. Despite broad spectrum and rapid bactericidal activity, ciprofloxacin-resistant bacteria are isolated particularly amongst $P$. aeruginosa and staphylococci. As ciprofloxacin is available for both oral and parenteral administration, it has been used extensively in the treatment of patients with cystic fibrosis. However, resistant strains of $P$. aeruginosa have been isolated during such treatment. Ravizzola et al..$^{147}$ examined two routine clinical isolates and their in-vitro ciprofloxacinresistant variants whose $\mathrm{MICs}$ were $>200 \mathrm{mg} / \mathrm{L}$ and $50 \mathrm{mg} / \mathrm{L}$ respectively. These strains were injected intraperitoneally into mice and the LD50s were calculated. The authors concluded that these ciprofloxacin-resistant strains were less virulent than the susceptible parent strains. A change in colony form (from large/rough to small/rough) was observed. The results suggested that resistance may be associated to a decrease in virulence.

In conclusion, since resistance and virulence genes can be harboured on plasmids and, occasionally, on the same plasmid, excessive use of antibiotics may favour (i) the spread of such plasmids harbouring these two types of genes, and (ii) the formation of such plasmids harbouring the two kinds of markers. Conversely, bacteria exhibiting changes usually associated with chromosomal mutations showed a reduction in virulence and infectivity but rarely a change in immunogenicity. Clearly agents able to select such resistance mechanisms should be used cautiously in circumstances where such mutations may be readily expressed because, although the strains appear to be less virulent, they are still resistant to therapy. Nevertheless, these chromosomally resistant mutant strains may be useful in the development of new bacterial vaccines in the light of their immunogenic but non-pathogenic properties.
SENSITIVITY OF ANTIBIOTIC RESISTANT BACTERIA TO OPSONOPHAGOCYTOSIS IN VITRO: IMPLICATIONS FOR CLINICAL INFECTIONS AND THERAPY

\section{G. Gemmell}

Department of Bacteriology, Medical School, University of Glasgow, Royal Infirmary, Glasgow

Since the advent of penicillin in 1940 and its subsequent use in the treatment of staphylococcal and other infections, concurrent resistance to the drug has been recognised amongst a hitherto susceptible bacterial population. In particular, the development of methicillin as a therapeutic drug followed the recognition that Staphylococcus aureus readily developed resistance to penicillin by the induction of a $\beta$-lactamase enzyme. Stereochemical features of methicillin prevented destruction of the antibiotic by the enzyme. However, resistance to this drug is now possible through alteration in the drug target proteins and methicillin-resistant $S$. aureus (MRSA) are now a clinical problem world-wide. ${ }^{148}$ Cross-resistance to other penicillins and cephalosporins, as well as resistance to drugs with different biochemical actions, is now found amongst this group of organisms.

MRSA strains are important nosocomial pathogens. They were first described in the early 1960 s and outbreaks of MRSA infection were described subsequently in Great Britain, Europe, the USA and Australia. With the exception of a single strain causing clinical problems in London and the South-East of England (named EMRSA-1) ${ }^{149}$ most outbreaks of infection with MRSA have been readily contained. This has led to the suggestion that such strains are generally less virulent than their methicillin-sensitive counterparts (MSSA). Isolates of $S$. aureus from patients with primary staphylococcal sepsis are still rarely multiresistant whereas those patients with MRSA usually have underlying disease, e.g., MRSA strains isolated from patients in a Burns Unit succeeded in colonising the most severely burned individuals but rarely spread elsewhere in the hospital. ${ }^{150}$ In terms of patient management, it would be useful to be able to distinguish strains that are potentially 
epidemic from non-epidemic or sporadic strains. One study has shown that production of low levels of protein $A$ and high levels of coagulase may be predictive of potentially epidemic strains. ${ }^{151}$ Some corroboration of these findings has been shown by others, who also demonstrated production of similar amounts of $\alpha, \gamma$ and $\delta$ haemolysins in MRSA and MSSA. ${ }^{152}$

With this background, it seemed logical to look for differences in host response to infection as a predictor of susceptibility to infection by MRSA. Measurement of various parameters of neutrophil function in vitro is possible and by so doing the expression or otherwise or surface components inimical to opsonophagocytosis might be detected. In addition, it is possible to compare neutrophil functions in normal and immunocompromised hosts.

Since 1985, the Royal Infirmary, Glasgow, has witnessed a succession of multi-resistant $S$. aureus strains with differing antibiotic susceptibility patterns. Patients admitted to the Burns Unit became colonised with a strain resistant to penicillin, erythromycin and fucidin (PEF). Sometime thereafter, a strain resistant to penicillin, erythromycin, methicillin and gentamicin (PEMG) appeared in these patients to the exclusion of the former strain. Strains with different antibiotic sensitivity patterns were chosen for measurement of their susceptibility to serum opsonisation and subsequent phagocytosis by neutrophils. However, no significant differences between the strains were found. ${ }^{153}$ Similar results have been reported also by others. ${ }^{152}$ suggesting that the observed changes in protein A expression are not in themselves sufficient to alter bacterial susceptibility to phagocytosis or that some compensation has taken place in the MRSA strains deficient in protein A.

Extension of these methods to neutrophils obtained from immunocompromised (i.e., burned) patients revealed that the host status was important in determining how MRSA were handled. Immediately after burn injury, patients' neutrophils were markedly depressed in terms of their ability to phagocytose MRSA and this change lasted for several days before normal phagocytic efficacy returned. To some extent, these differences could be attributed to difference in the opsonic activity of the patients' serum (table XI). Therefore, these findings would support the concept that drug resistance per se does not predetermine virulence in vivo except amongst immunocompromised patients, in whom humoral and cellular defects can be recognised.

It is realised that the drug-resistant $S$. aureus strains used in the preceding studies may or may not have had a common genetic background and cannot, therefore, be properly compared to each other or to antibiotic-sensitive strains. In an attempt to answer this criticism, a different approach has been followed with regard to the development of fluoroquinolone resistance in S. aureus and Pseudomonas aeruginosa.

The primary action of the quinolones is on DNA gyrase, although the cidal mechanism may involve a series of events. ${ }^{154}$ Resistance to drugs of this type is based upon the possession of an altered DNA gyrase, with the A sub-units being intimately involved. Mutations affecting synthesis of a particular outer membrane protein and permeability have been described also. Many of these mutant strains have appeared during therapy and have constituted a risk to the patient as well as a threat to the choice of the quinolones in therapy.

Serial subculture of many bacterial species in the presence of sub-inhibitory concentrations of norfloxacin, ciprofloxacin, ofloxacin, enoxacin or pefloxacin results in the selection of resistance; Escherichia coli may be an exception. Crossresistance between the five drugs was readily demonstrable. ${ }^{155}$ This technique has been used to provide quinoloneresistant variants derived from an original quinolonesensitive strain as targets for measurement of their comparative susceptibility to phagocytosis. Ciprofloxacin and ofloxacin were used as selector drugs. No differences were recognisable in ingestion by neutrophils between the quinolone-resistant offspring and the $S$. aureus or $P$. aeruginosa parent strains. ${ }^{156}$ However, when their ability to induce a respiratory burst in the neutrophils was measured, some differences were found between the strains. Variants of $S$. aureus expressing low or intermediate level resistance to the quinolones were less able to generate a respiratory burst than the original strain. In contrast, similar strains of $P$. aeruginosa appeared more capable of stimulating the neutrophils in this assay. In addition, there was considerable strain-to-strain variation in neutrophil interaction which could not be explained either by their innate susceptibility to phagocytic ingestion or their level of drug resistance. Table XII illustrates some of these results. It remains to be seen whether the drug-induced variants differ in other respects from their parent strains. Preliminary evidence with $S$. aureus suggests that their ability to elaborate various exotoxins (e.g., $\alpha$-haemolysin, coagulase) may be altered. Whether their structural topography is also modified during the development of drug resistance is still to be investigated.

On the basis of current experimental approaches there is little evidence to suggest that development of drug resistance results in "superbugs" capable of initiating more serious infections than their drug-sensitive counterparts, except, perhaps, in causing nosocomial infection among immunocompromised patients. In this context, it would be appropriate to extend the studies to bacterial pathogens in which drug resistance has developed during antibiotic therapy. The selective pressure provided by the antibiotic ciprofloxacin used in the treatment of peritonitis in patients undergoing chronic ambulatory peritoneal dialysis has provided drug-sensitive and drug-resistant strains of $S$. epidermidis and $S$. haemolyticus. However, no differences in bacterial susceptibility to opsonophagocytosis were detected.

\section{THE CLINICAL IMPLICATIONS OF ACQUIRED BACTERIAL RESISTANCE}

\section{R. N. Grüneberg}

Department of Microbiology, University College Hospital, London WCIE $6 A U$

The general implications of acquired bacterial resistance to antimicrobial agents are very great. The explosive growth of a new industry of bacterial genetics has been given a

Table XI. Differences between serum from burned patients A and B and normal serum in opsonisation of strains of $S$. aureus

\begin{tabular}{|c|c|c|c|c|c|c|}
\hline \multirow{2}{*}{$\begin{array}{l}\text { Target } \\
\text { strain }\end{array}$} & \multicolumn{6}{|c|}{$\begin{array}{l}\text { Percentage ingested by PMNL after opsonisation with } \\
\text { normal serum } \quad \text { patient A serum patient B serum }\end{array}$} \\
\hline & $1 \%$ & $10 \%$ & $1 \%$ & $10 \%$ & $1 \%$ & $10 \%$ \\
\hline $\begin{array}{r}\text { PRF } \\
\text { PFMG }\end{array}$ & 12.5 & $23 \cdot 1$ & 3.9 & $10 \cdot 8$ & 1.6 & 3.6 \\
\hline PEMG & $17 \cdot 2$ & $22 \cdot 5$ & $13 \cdot 2$ & $25 \cdot 2$ & 1.0 & 9.5 \\
\hline
\end{tabular}


Table XII. Induction of repiratory burst in PMNL following exposure to quinolone-sensitive and quinolone-resistant strains of $S$. aureus

\begin{tabular}{ll|cc}
\hline \multirow{2}{*}{ Strain } & $\begin{array}{c}\text { Peak chemiluminescence (cpsc) after } \\
\text { opsonisation with serum }\end{array}$ \\
& $\begin{array}{l}\text { Drug } \\
\text { resistance }\end{array}$ & $1 \%$ & $10 \%$ \\
\hline BRO $_{1}$ & None & 0.27 & 0.27 \\
& Ciprofloxacin & 0.19 & 0.36 \\
$\mathrm{LH}_{4}$ & Ofloxacin & 0.41 & 0.45 \\
& None & 0.40 & 0.36 \\
& Ciprofloxacin & 0.24 & 0.35 \\
& Ofloxacin & 0.10 & 0.19 \\
\hline
\end{tabular}

powerful impetus by the stimulus of enquiry into the mechanisms of acquired bacterial resistance and has generated considerable activity in academic departments of medical microbiology and research laboratories. A second consequence has been to make medical microbiologists much more "clinical" and much less laboratory based. In the UK, there are approximately 400 consultant medical microbiologists with an infrastructure of junior medical staff, specialised laboratory staff and whole sections of laboratories, for the basis of development has been the existence of antibiotics and the linked relationship with antibiotic resistance. Before the antibiotic era there were hardly any specialist microbiologists in hospitals in the UK ; there were relatively small numbers in University departments whose functions were related to teaching and research.

The development of antibiotic resistance has added greatly to the interest of medical microbiology and has provided opportunities for international links, often through the support of the pharmaceutical industry for conferences at home and abroad. The development of the antimicrobial part of the pharmaceutical industry has been very striking. Had there been no need to develop this industry because bacteria had not acquired resistance, there would be very different patterns of prescribing within hospitals, where one fifth of the drugs budget is now allocated to antimicrobial agents, and a corresponding reduction in the interest of the industry in microbiologists.

All drugs have certain common limitations on their usethe nature and frequency of side effects, and cost. Antimicrobial agents have a third problem which has generated the antibiotics industry and medical microbiology as a speciality -acquired bacterial resistance to antibiotics.

\section{Selection of resistant organisms}

In the early days of the antimicrobial era, most infections were caused by organisms, such as staphylococci, streptococci, and, very occasionally, coliform organisms, which were inherently antibiotic-sensitive. Over subsequent decades, selection pressures produced by the widespread use of antibiotics, whether for appropriate or inappropriate reasons, have resulted in the emergence of new groups of major pathogens as causes of infections. Often this has led to the emergence of organisms of which microbioligists were barely aware before the advent of antimicrobial agents; infections caused by Pseudomonas aeruginosa, and even by other Pseudomonas spp., by Klebsiella, Enterobacter, Serratia, Arizona and Citrobacter spp. and by many other gramnegative species, by enterococci, and by resistant staphylococci, whether coagulase-negative or coagulase-positive, are now common. The pressures for the emergence of these oragnisms as pathogens have been, on the one hand technological change, such as the increasingly widespread use of ind welling vascular catheters or prosthetic devices, or more heroic surgical procedures, and, on the other hand, the attempt to prevent these ever more exposed patients succumbing to infections by the widespread use of antibiotics, whether given prophylactically or therapeutically.

\section{New drugs}

In the classical era of the development of new antimicrobial agents, extending to the late 1950 s, although antibiotic resistance was emerging it has not done so to any great extent and several powerful agents were available that covered nearly all the pathogens that were commonly seen in clinical practice at that time; penicillin, streptomycin, tetracycline, chloramphenicol, sulphonamide, erythromycin, ampicillin, carbenicillin, methicillin, the first generation cephalosporins and metronidazole were all available.

However, many of those drugs, useful though they were, had limitations on their use because of difficulty of administration or, in cases such as streptomycin, toxicity. There would, perhaps, have been some development of new drugs even in the absence of bacterial resistance, as attempts to develop more convenient versions of existing drugs which would have been easier to administer and perhaps less toxic. It is reasonable to speculate that there would not have been the development of the semi-synthetic $\beta$-lactam agents-the cephalosporins, monobactams, augmentin, etc -or of trimethoprim and co-trimoxazole, and that the massive development of the aminoglycosides, and the quinolones and glycopeptide antibiotics, would not have occurred without the major stimulus of bacterial resistance. If it were not for the problem of resistance, most of these relatively new antimicrobial agents would have offered little to improve patient management.

\section{Implications for patients}

The response of the medical profession to the problem of resistance has been to use higher doses of the older drugs than would otherwise have been the case, or to combine drugs, as in the treatment of tuberculosis, to overcome the actual or perceived risk of resistance to single agents, or, alternatively, to use more recently developed drugs which may be difficult to administer, toxic and costly.

Some drugs are difficult to administer because they have to be given intravenously, commonly in substantial doses, generally necessitating the positioning of long intravenous catheters, which essentially ties the patient to a hospital bed and makes him or her immobile; there is also the administration, in some cases, of a heavy sodium load. There are well documented risks of morbidity and mortality relating to the length of time for which an intravenous catheter has to remain in place.

Toxicity and side effects present considerable problems in relation to monitoring levels of the agents in serum and the cost of this monitoring, both in terms of laboratory costs and 
in terms of potential litigation when patients have semipredictable side effects related either to unusual sensitivity to the drug or to long administration of the drug for good clinical reasons. The cost of monitoring and of litigation is substantially under-estimated by the medical profession. The direct cost of the drug also may be very considerable. Pencillin G, $600 \mathrm{mg}$ given 6 hourly, costs a few pence per day. The cost of replacing penicillin $G$ by alternatives such as vancomycin, cephalosporins, etc., may be tens of pounds per day, with the result that excess money spent on the new drugs cannot be spent on more desirable objectives. There are also associated costs in giving drugs, both for the giving system and for the labour of administering the treatment.

\section{Examples of current clinical problems}

A recent problem concerns a 6-month-old child with meningitis caused by a pneumococcus with diminished sensitivity to penicillin. Initially, penicillin was given, before it was recognised that the pneumococcus was not fully sensitive, and there was no significant clinical response. Once the problem was recognised, chloramphenicol treatment was instituted but this has caused considerable anxiety because of the need to give a potentially toxic drug to a child who would otherwise not have received it.

In another specialty, cardiac surgeons have used $\beta$-lactam antibiotics combined with an aminoglycoside, prophylactically, to reduce post-operative sternal would infection. Such infections are most commonly caused by coagulase-negative staphylococci, which are resistant to methicillin in $60 \%$ of cases, or by Staphylococcus aureus. Because even very short courses of aminoglycosides given prophylactically may give rise to toxicity, there is increasing pressure to use glycopeptide antibiotics prophylactically.

\section{References}

1. O'Grady F. Trimethoprim-sulfamethoxazole: a reappraisal. Canad Med Assoc J 1975; 112 Suppl: 5S-7S.

2. Brumfitt W, Hamilton-Miller JMT. Co-trimoxazole or trimethoprim alone? A viewpoint on their relative place in therapy. Drugs 1982; 24: 453-458.

3. Hamilton-Miller JMT. Resistance to antibacterial agents acting on antifolate metabolism. In: Bryan LE (ed) Antimicrobial drug resistance. Orlando, Academic Press. 1984: 173-190.

4. Amyes SGB, Towner KJ. Trimethoprim resistance; epidemiology and molecular aspects. J Med Microbiol 1990; 31: $1-19$.

5. Towner KJ. Resistance to trimethoprim among urinary tract isolates in the United Kingdom. Rev Infect Dis 1982; 4: 456-460.

6. Goldstein FW, Papadopoulou B, Acar JF. The changing pattern of trimethoprim resistance in Paris, with a review of worldwide experience. Rev Infect Dis 1986; 8: 725-737.

7. Towner KJ, Slack RCB. Effect of changing selection pressures on trimethoprim resistance in Enterobacteriaceae. Eur $J$ Clin Microbiol 1986; 5: 502-506.

8. Radström P, Swedberg G. RSF 1010 and a conjugative plasmid contain sulII, one of two known genes for plasmid-borne sulfonamide resistance dihydropteroate synthase. Antimicrob Agents Chemother 1988; 32: 1684-1692.

9. Sundström L, Radström P, Swedberg G, Sköld O. Site-specific recombination promotes linkage between trimethoprimand sulfonamide-resistance genes. Sequence characterization of $d h f r V$ abd sulI and a recombination active locus of Tn21. Mol Gen Genet 1988; 213 : 191-201.

10. Swedberg G, Sköld $O$. Characterization of different plasmidborne dihydropteroate synthases mediating bacterial resistance to sulfonamides. $J$ Bacteriol $1980 ; 142$ : $1-7$.

11. Pinney RJ, Smith JT. Joint trimethoprim and sulphamethoxazole resistance in bacteria infected with $\mathrm{R}$ factors. $\mathrm{J} \mathrm{Med}$ Microbiol 1973; 6: 13-19.

\section{Doomwatch}

There is steadily progressive erosion of the usefulness of antibiotics by rising tide of acquired resistance in pathogenic bacteria. Total inability to control resistant bacteria is, so far, a rarity. However, doctors being driven to use secondor third-line drugs, or antibiotic combinations, rather than the first choices of previous years. A heavy cost in side effects, ecological damage, preventable hospitalisation, morbidity and mortality, and in money, is being paid and will increasingly be paid.

\section{Concluding remarks by J. T. Smith}

In the "good old days", a single lecture describing bacterial resistance to antibacterial agents would nicely encompass all there was to know on the subject. However, as clinical isolates exhibiting resistance to more and more drugs became more frequent (more often than not resulting from $R$ plasmids), whole conferences on resistance to but a single class of antibacterial agent became normal. Although such a fashion had technical merit, discussion of bacterial resistance became so fragmented that few indeed could retain an overview of the problem. The meeting that provided the basis for this review article brought together investigators with a wide range of expertise across the full spectrum of antibiotic resistance and helped speakers and audience alike to stay abreast of this most important topic.

We thank Bayer UK for supporting the meeting on which this article is based, which has permitted a forum where problems of antibiotic resistance could be frankly discussed.

12. Amyes SGB, Smith JT. Thymineless mutants and their resistance to trimethoprim. J Antimicrob Chemother 1975: 1: 85-89.

13. Grey D, Hamilton-Miller JMT, Brumfitt W. Incidence and mechanisms of resistance to trimethoprim in clinically isolated gram-negative bacteria. Chemotherapy 1979; 25 : $147-156$.

14. Gutmann L, Williamson R, Moreau N et al. Cross-resistance to nalidixic acid, trimethoprim, and chloramphenicol associated with alterations in outer membrane proteins of Klebsiella, Enterobacter and Serratia. J Infect Dis 1985; 151: 501-507.

15. Amyes SGB, Towner KJ, Carter GI, Thomson CJ, Young H-K. The type VII dihydrofolate reductase: a novel plasmid-encoded trimethoprim-resistant enzyme from gram-negative bacteria isolated in Britain. $J$ Antimicrob Chemother 1989; 24: 111-119.

16. Sundström $L$. The genes of trimethoprim resistance and their recominational dissemination. Acta Pharm Nord 1989; 1 375.

17. Towner KJ, Carter GI, Young H-K, Amyes SGB. Detection of novel trimethoprim resistance determinants in the United Kingdom using biotin-labelled DNA probes. Epidemiol Infect 1991; 106: 63-70.

18. Thomson CJ, Towner KJ, Young H-K, Amyes SGB. Identifcation and cloning of the type IIIA plasmid-encoded dihydrofolate reductase gene from trimethoprim-resistant gram-negative bacteria isolated in Britain. J Med Microbiol $1990 ; 31$ : 213-218.

19. Towner KJ, Carter GI. Cloning of the type VII trimethoprim resistant dihydrofolate reductase and identification of a specific DNA probe. FEMS Microbiol Lett 1990; 70 : 19 22.

20. Thomas CJ, Barg N, Amyes SGB. N-terminal amino acid sequence of the novel type IIIB trimethoprim-resistant plasmid-encoded dihydrofolate reductase from Shigella sonnei. J Gen Microbiol 1990; 136: 673-677. 
21. Thomson CJ, Young H-K, Amyes SGB. N-terminal aminoacid sequence and subunit structure of the type IV trimethoprim-resistant plasmid-encoded dihydrofolate reductase. J Med Microbiol 1990; 32: 153-158.

22. Wylie BA, Koornhof HJ. Nucleotide sequence of the type VI dihydrofolate reductase encoded by pUK672. J Med Microbiol $1991 ; 35: 214-218$

23. Abrahams EP, Chain E. An enzyme from Bacteria able to destroy penicillin. Nature $1940 ; 146: 837$.

24. Neu HC. Contribution of beta-lactamases to bacterial resistance and mechanisms to inhibit beta-lactamases. Am J Med 1985; 79 Suppl 5B : 2-12.

25. Anderson ES, Datta N. Resistance to penicillins and its transfer in Enterobacteriaceae. Lancet 1985; 1: 407-409.

26. Richmond, $\mathbf{M H}$, Sykes RB. The $\beta$-lactamases of gram-negative bacteria and their possible physiological role. In: Rose AH, Tempest DW (eds) Advances in microbial physiology, no. 9. London, Academic Press. 1967: 31-88

27. Ambler RP. The structure $\beta$-lactamases. Phil Trans Roy Soc Lond 1980: 289: 321-331.

28. Jaurin B, Grundström T. ampC cephalosporinase of Escherichia coli $\mathrm{K}-12$ has a different evolutionary origin from that of $\beta$-lactamases of the penicillinase type. Proc Natl Acad Sci USA 1981: $78: 4807-4901$

29. Huovinen P, Huovinen S, Jacoby GA. Sequence of PSE-2 $\beta$ lactamase. Antimicrob Agents Chemother 1988; 32: 134 136.

30. Dale JW, Godwin D, Mossakowska D, Stephenson P, Wall S. Sequence of the OXA2 $\beta$-lactamase: comparison with other penicillin-reactive enzymes. FEBS Lett 1985; 191 : $39-44$.

31. Bicknell R, Emanuel EL, Gagnon J, WaleySG. The production and molecular properties of the zinc $\beta$-lactamase of Pseudomonas maltophilia IID 1275. Biochem $J$ 1985; 229 : $791-797$

32. Huletsky, A. Couture F, Levesque RC. Nucleotide sequence and phylogeny of SHV-2 $\beta$-lactamase. Antimicrob Agents Chemother 1990; 34: 1725-1732.

33. Sougakoff $W$, Goussard $S$, Courvalin P. The TEM-3 $\beta$ lactamase, which hydrolyzes broad-spectrum cephalosporins, is derived from the TEM-2 penicillinase by two amino acid substitutions. FEMS Microbiol Lett 1988 ; 56 : $343-348$

34. Matthew M, Harris AM, Marshall MJ, Ross GW. The use of analytical isoelectric focusing for detection and identification of $\beta$-lactamases. $J$ Gen Microbiol $1975 ; 88$ : 169 178

35. Roy C, Foz A, Segura C, Tirado M, Fuster C, Reig R. Plasmiddetermined $\beta$-lactamases identified in a group of 204 ampicillin-resistant Enterobacteriaceae. $J$ Antimicrob Chemother $1983 ; 12: 507-510$

36. Simpson IN, Knothe H, Plested SJ, Harper PB. Qualitative and quantitative aspects of $\beta$-lactamase production as mechanism of $\beta$-lactam resistance in a survey of clinical isolates from faecal samples. J Antimicrob Chemother $1986 ; 17: 725-737$

37. Reid AJ, Simpson IN, Harper PB, Amyes SGB. Cephaloridine resistance in gram-negative bacteria isolated in Scotland. $J$ Pharm Pharmacol 1988; 40: 571-573.

38. Nandivada LS, Amyes SGB. Plasmid-mediated $\beta$-lactam resistance in pathogenic gram-negative bacteria isolated in South India. $J$ Antimicrob Chemother 1990; 26: 279290.

39. Amyes SGB. The success of plasmid-encoded resistance genes in clinical bacteria: an examination of plasmid-mediated ampicillin and trimethoprim resistance genes and their resistance mechanisms. J Med Microbiol 1990; 28 : 73-83.

40. Payne DJ, Marriott MS, Amyes SGB. Characterisation of a unique ceftazidime-hydrolysing $\beta$-lactamase, TEM-E2. $J$ Med Microbiol 1990; 32: 131-134.

41. Kliebe C, Nies BA, Meyer JF, Tolxdorff-Neutzling RM, Wiedemann B. Evolution of plasmid-coded resistance to broad-spectrum cephalosporins. Antimicrob Agents Chemother $1985 ; 28$ : 302-307.

42. Petit A, Gerbaud G, Sirot D, Courvalin P, Sirot J. Molecular epidemiology of TEM-3 (CTX-1) $\beta$-lactamase. Antimicrob Agents Chemother 1990; 34: 219-224.

43. Rice LB, Willey SH, Papanicolaou GA et al. Outbreak of ceftazidime resistance caused by extended-spectrum $\beta$ - lactamase at a Massachusetts chronic-care facility. Antimicrob Agents Chemother 1990; 34: 2193-2199.

44. Payne DJ, Amyes SGB. Transferable resistance to extendedspectrum $\beta$-lactams : a major threat or a minor inconvenience? J Antimicrob Chemother 1991 ; $27: 255-261$

45. Woodford N, Payne DJ, Johnson AP et al. Transferable cephalosporin resistance not inhibited by clavulanate in Escherichia coli. Lancet $1990 ; 336: 253$.

46. Bobrowski MM, Matthew M, Barth PT et al. Plasmiddetermined $\beta$-lactamase indistinguishable from chromosomal $\beta$-lactamase of Escherichia coli. J Bacteriol 1976; 125: $149-157$

47. Gutmann L, Kitzis MD, Billot-Klein D et al. Plasmidmediated $\beta$-lactamase (TEM-7) involved in resistance to ceftazidime and aztreonam. Rev Infect Dis $1988 ; 10 ; 860$ 866.

48. Suttcliffe JA, Gootz, TD, Barrett, JF. Biochemical characteristics and physiological significance of major DNA topoisomerases. Antimicrob Agents Chemother 1989; 33: 2027-2033.

49. Fisher LM. DNA supercoiling and gene expression. Nature $1984 ; 307: 686-687$.

50. Dorman CJ, Bhriain NN, Higgins CF. DNA supercoiling and environmental regulation of virulence gene expression in Shigella flexneri. Nature $1990 ; 344: 789-792$.

51. Courvalin P. Plasmis-mediated 4-quinolone resistance: a rea or apparent absence? Antimicrob Agents Chemother 1990; 34: $681-684$.

52. Lewin CS, Allen RA, Amyes SGB. Potential mechanisms of resistance to the modern fluorinated 4-quinolones. $J \mathrm{Med}$ Microbiol 1990; 31: 153-161.

53. Ubukata K, Itoh-Yamashita $\mathbf{N}$, Konno $\mathbf{M}$. Cloning and expression of the nor $A$ gene for fluoroquinolone resistance in Staphylococcus aureus. Antimicrob Agents Chemother $1989 ; 33: 1535-1539$.

54. Yoshida H, Bogaki M, Nakamura S, Ubukata K. Nucleotide sequence of the nor $A$ gene of Staphylococcus aureus conferring quinolone resistance. Abstracts of the 3rd International Symposium on New Quinolones No. 160 1990: 202.

55. Nakamura $S$, Nakamura $M$, Kojima $T$, Yoshida $H$ gyr $A$ and gyr $B$ mutations in quinolone-resistant strains of Escherichia coli. Antimicrob Agents Chemother 1989; 33: 254 255.

56. Yoshida H, Nakamura M, Bogaki M, Nakamura S. Proportion of DNA gyrase mutants among quinolone-resistant strains of Pseudomonas aeruginosa. Antimicrob Agents Chemother $1990 ; 34: 1273-1275$

57. Robillard NJ. Broad-host-range gyrase A gene probe. Antimicrob Agents Chemother 1990; 34: 1889-1894.

58. Hooper DC, Wolfson JS, Souza KS, Tung C, McHugh GL Swartz MN. Genetic and biochemical characterization of norflexocin resistance in Escherichia coli. Antimicrob Agents Chemother 1986; 29 : 639-644.

59. Aoyama H, Sato K, Kato T, Hirai K, Mitsuhashi S Norfloxacin resistance in a clinical isolate of Escherichia coli. Antimicrob Agents Chemother 1987; 31 : 1640-1641

60. Hirai K, Suzue S, Irikura T, Iyobe S, Mitsuhashi S. Mutations producing resistance to norfloxacin in Pseudomonas aeruginosa. Antimicrob Agents Chemother 1987; 31: 582586

61. Inoue $Y$, Sato $K$, Fujii $T$ et al. Some properties of subunits of DNA gyrase from Pseudomonas aeruginosa PAO1 and its nalidixic acid-resistant mutant. $J$ Bacteriol 1987; 169: 2322-2325.

62. Robillard NJ, Scarpa AL. Genetic and physiological characterization of ciprofloxacin resistance in Pseudomonas aeruginosa PAO. Antimicrob Agents Chemother 1988; 32 535-539.

63. Setlow JK, Cabrera-Juárez E, Albritton WL, Spikes D, Mutschier A. Mutations affecting gyrase in Haemophilus influenzae. J Bacteriol 1985; 164 : 525-534.

64. Aoyama H, Sato K, Fujii T, Fulimaki K, Inoue M, Mitsuhashi S. Purification of Citrobacter freundii DNA gyrase and inhibition by quinolones. Antimicrob Agents Chemother $1988 ; 32: 104-109$

65. Fujimaki K, Fujii T, Aoyama $\mathrm{H}$ et al. Quinolone resistance in clinical isolates of Serratia marcescens. Antimicrob Agents Chemother 1989; 33: 785-787. 
66. Yoshida H, Kojima T, Yamagishi J, Nakamura S. Quinoloneresistant mutations in gyrA gene of Escherichia coli. Mol Gen Genet 1988; 211 : 1-7.

67. Dimri GP, Das HK. Cloning and sequence analysis of gyrA gene of Klebsiella pneumoniae. Nucleic Acids Res 1990; 18 : 151-156.

68. Hopewell R, Oram M, Briesewitz R, Fisher LM. DNA cloning and organization of the Staphylococcus aureus gyrA and gyr $B$ genes: close homology among gyrase proteins and implications for 4-quinolones action and resistance. $J$ Bacteriol 1990; 172: 3481-3484.

69. Yoshida H, Bogaki M, Nakamura S. Quinolone resistancedetermining region in the DNA gyrase gyrA gene of Escherichia coli. Antimicrob Agents Chemother 1990; 34: 1271-1272.

70. Cullen ME, Wyke AW, Kuroda, R, Fisher LM. Cloning and characterization of a DNA gyrase A gene from Escherichia coli that confers clinical resistance to the 4-quinolones. Antimicrob Agents Chemother 1989; 33: 886-894.

71. Sreedharan S, Oram M, Jensen B, Petersen LR, Fisher LM. DNA gyrA mutations in ciprofloxacin strains of Staphylococcus aureus: close similarity with quinolone resistance mutations in Esherichia coli. J Bacteriol 1990; 172: 72607262.

72. Yamagishi J, Yoshida H, Yamayoshi M, Nakamura S. Nalidixic acid-resistant mutations of the gyr $B$ gene of Escherichia coli. Mol Gen Genet 1986; 204: 367-373.

73. Hirai K, Aoyama $\mathrm{H}$, Irikura $\mathrm{T}$, lyobe $\mathrm{S}$, Mitsuhashi S. Differences in susceptibility to quinolones of outer membrane mutants of Salmonella typhimurium and Escherichia coli. Antimicrob Agents Chemother 1986; 29: 535538.

74. Chapman JS, Georgopapadakou NH. Routes of quinolone permeation in Escherichia coli. Antimicrob Agents Chemother $1988 ; 32$ : 438-442.

75. Cohen SP, Hooper DC, Wolfson JS, Souza KS, McMurry LM, Levy SB. Endogenous active efflux of norfloxacin in susceptible Escherichia coli. Antimicrob Agents Chemother $1988 ; 32$ : 1187-1191.

76. Chamberland S, Bayer AS, Schollaardt T, Wong SA, Bryan LE. Characterization of mechanisms of quinolone resistance in Pseudomonas aeruginosa strains isolated in vitro and in vivo during experimental endocarditis. Antimicrob Agents Chemother 1989; 33: 624-634.

77. Piddock LJV, Wise R. Mechanisms of resistance to quinolones and clinical perspectives. J Antimicrob Chemother 1989; 23: $475-483$.

78. Hooper DC, Wolfson JS, Souza KS, Ng EY, McHugh GL, Swartz MN. Mechanisms of quinolone resistance in Escherichia coli: characterization of $n f x B$ and $c f x B$, two mutant resistance loci decreasing norfloxacin accumulation. Antimicrob Agents Chemother 1989; 33: 283-290.

79. Daikos GL, Lolans VT, Jackson GG. Alteractions in outer membrane proteins of Pseudomonas aeruginosa associated with selective resistance to quinolones. Antimicrob Agents Chemother 1988; 32: 785-787.

80. Fukuda $\mathbf{H}$, Hosaka M, Hirai K, Iyobe $S$. New norfloxacin resistance gene in Pseudomonas aeruginosa PAO. Antimicrob Agents Chemother 1990; 34: 1757-1761.

81. Kresken M, Wiedemann, B. Development of resistance to nalidixic acid and the fluoroquinolones after the introduction of norfloxacin and ofloxacin. Antimicrob Agents Chemother 1988; 32: 1285-1288.

82. Grimm H. Aktuelle erregerempfindlichkrit gegenuber ciprofloxacin in klinik und praxis-vergleich mit anderen wirkstoffen. Fortschritte der Antimikrobiellen und Antineoplastischen Chemkotherapie 1989: 33-47.

83. Smith SM, Eng RHK, Bais P, Fan-Havard P, Tecson-Tumang F. Epidemiology of ciprofloxacin resistance among patients with methicillin-resistant Staphylococcus aureus. $J$ Antimicrob Chemother 1990; $26: 567-572$.

84. Kato N, Miyauchi M, Muto $\mathrm{Y}$, Watanabe, K, Ueno K. Emergence of fluoroquinolone resistance in Bacteroides fragilis accompanied by resistance to $\beta$-lactam antibiotics. Antimicrob Agents Chemother 1988; 32: 1437-1438.

85. Lewis DA, Hawkey PM, Watts JA et al. Infection with netilmicin resistant Serratia marcescens in a special care baby unit. Br Med J 1983; 287: 1701-1705.

86. Hancock REW, Raffle VJ, Nicas TI. Involvement of the outer membrane in gentamicin and streptomycin uptake and killing in Pseudomonas aeruginosa. Antimicrob Agents Chemother 1981 ; 19 : 777-785.

87. Hancock REW. Aminoglycoside uptake and mode of actionwith special reference to streptomycin and gentamicin. I. Antagonists and mutants. $J$ Antimicrob Chemother 1981 ; 8: $249-276$.

88. MacArthur RD, Lolans V, Zar FA, Jackson GG. Biphasic, concentration-dependent and rate-limited, concentrationindependent bacterial killing by an aminoglycoside antibiotic. $J$ Infect Dis $1984 ; 150$ : 778-779.

89. Bryan LE. Cytoplasmic membrane transport and antimicrobial resistance. In: Bryan LE (ed) Microbial resistance to drugs. Berlin, Springer Verlag. 1989: 35-57.

90. Schlessinger D. Failure of aminoglycoside antibiotics to kill anaerobic, low-pH, and resistant cultures. Clin Microbiol Rev 1988; 1: 54-59.

91. Dickie P, Bryan LE, Pickard MA. Effect of enzymic adenylation on dihydrostreptomycin accumulation in Escherichia coli carrying an R-factor: model explaining aminoglycoside resistance by inactivating mechanisms. Antimicrob Agents Chemother 1978; 14: 569-580.

92. Bryan LE. Aminoglycoside resistance. In: Bryan LE (ed) Antimicrobial drug resistance. Orlando, Academic Press. 1984: 241-277.

93. Gilleland HE, Gibson JA, Champlin FR. Adaptive resistance to aminoglycoside antibiotics in Pseudomonas aeruginosa. J Med Microbiol 1989; 29 : 41-50.

94. D'Aoust, J-Y, Daley E, Crozier M, Sewell AM. Pet turtles: a continuing international threat to public health. Am J Epidemiol 1990; 132: 233-238.

95. Lovering AM, Bywater MJ, Holt HA, Champion HM, Reeves DS. Resistance of bacterial pathogens to four aminoglycosides and six other antibacterials and prevalence of aminoglycoside modifying enzymes in 20 UK centres. $J$ Antimicrob Chemother 1988; 22: 823-839.

96. Dornbusch K, Miller GH, Hare RS, Shaw KJ and the ESGAR Study Group. Resistance to aminoglycoside antibiotics in gram-negative bacilli and staphylococci isolated from blood. Report from a European collaborative study. $J$ Antimicrob Chemother 1990; 26: 131-144.

97. European Study Group on Antibiotic Resistance. In-vitro susceptibility to aminoglycoside antibiotics in blood and urine isolates consecutively collected in twenty-nine European Laboratories. Eur J Clin Microbiol. 1987; 6: 378-385.

98. Infectious Diseases Society of America. Report from the Antimicrobial Agents Committee. J Infect Dis 1987; 156: 700-705.

99. Phillips, I, King A, Shannon K. Prevalence and mechanisms of aminoglycoside resistance: a 10-year study. $\mathrm{Am} \mathrm{J} \mathrm{Med}$ $1986 ; 80$ Suppl 6B: 48-55.

100. Bengtsson S, Bernander S, Brorson JE et al. In-vitro aminoglycoside resistance of Gram-negative bacilli and staphylococci isolated from blood in Sweden 1980-1984. Scand $J$ Infect Dis 1986; 257-263.

101. Shimizu K. Kumada T, Hsieh W-C et al. Comparison of aminoglycoside resistance patterns in Japan, Formosa, and Korea, Chile, and the United States. Antimicrob Agents Chemother 1985; $28: 282-288$.

102. Huovinen P, Grönroos P, Herva E et al. Aminoglycoside resistance among blood culture isolates. J Clin Microbiol $1984 ; 20: 65-69$.

103. Moaz A, Shannon K, Phillips I. Mechanisms of gentamicin resistance in gram-negative bacilli in Riyadh, Kingdom of Saudi Arabia. J Antimicrob Chemother 1989; 24: 689698.

104. Van de Klundert JAM, Vliegenthart JS, Van Doorn E, Bongaerts GPA, Molendijk L, Mouton RP. A simple method for the identification of aminoglycoside-modifying enzymes. $J$ Antimicrob Chemother 1984; 14: 339 348.

105. Reynolds PE. Inhibitors of bacterial cell wall synthesis. In: Greenwood D, O'Grady F (eds) The scientific basis of antimicrobial chemotherapy. Symp Soc Gen Microbiol 1985; 38: $13-40$.

106. Perkins HR. Vancomycin and related antibiotics. Pharmacol Ther 1982; 16: 191-197.

107. Barna JC, Williams DH. The structure and mode of action of 
glycopeptide antibiotics of the vancomycin group. Annu Rev Microbiol 1984; 38 : 339-357.

108. Jeffs PW, Nisbet LJ. Glycopeptide antibiotics: a comprehensive approach to discovery, isolation, and structure determination. In: Actor P, Daneo-Moore L, Higgins ML, Salton MRJ, Shockman GD (eds) Antibiotic inhibition of bacterial cell surface assembly and function. Washington, DC. American Society for Microbiology 1988: 509-530.

109. Reynolds PE. Structure, biochemistry and mechanism of action of glycopeptide antibiotics. Eur J Clin Microbiol Infect Dis 1989; 8: 943-950.

110. Orberg PK, Sandine WE. Common occurrence of plasmic DNA and vancomycin resistance in Leuconostoc spp. Appl Environ Microbiol 1984; 48; 1129-1133.

111. Uttley AHC, George RC, Naidoo $J$ et al. High-level vancomycin-resistant enterococci causing hospital infections. Epidem Inf 1989; 103: 173-181.

112. Shlaes DM, Bouvet A, Devine C, Shlaes JH, Al-Obeid S, Williamson $R$. Inducible, transferable resistance to vancomycin in Enterococcus faecalis A256. Antimicrob Agents Chemother 1989; 33: 198-203.

113. Williamson R, Al-Obeid S, Shlaes JH, Goldstein FW, Shlaes DM. Inducible resistance to vancomycin in Enterococct's faecium D366. J Infect Dis 1989; 159: 1095-1104.

114. Leclercq $\mathbf{R}$, Derlot E, Weber $\mathbf{M}$, Duval J, Courvalin $\mathbf{P}$. Transferable vancomycin and teicoplanin resistance in Enterococcus faecium. Antimicrob Agents Chemother 1989; 33: $10-15$.

115. Dutka-Malen S, Leclercq R, Coutant V, Duval J, Courvalin $P$. Phenotypic and genotypic heterogeneity of glycopeptide resistance determinants in gram-positive bacteria. Antimicrob Agents Chemother 1990; 34: 1875-1879.

116. Johnson AP, Uttley AH, Woodford N, George RC. Resistance to vancomycin and teicoplanin: an emerging clinical problem. Clin Microbiol Rev 1990; 3: 280-291.

117. Brisson-Noël A, Dutka-Malen S, Molinas C, Leclercq R, Courvalin $\mathrm{P}$. Cloning and heterospecific expression of the resistance determinant $\operatorname{van} A$ encoding high-level resistance to glycopeptides in Enterococcus faecium BM4147. Antimicrob Agents Chemother 1990; 34: 924-927.

118. Dutka-Malen S, Molinas C, Arthur M, Courvalin P. The VANA glycopeptide resistance protein is related to Dalanyl-D-alanine ligase cell wall biosynthesis enzymes. Mol Gen Genet 1990; 224 : 264-372.

119. Al-Obeid S, Gutmann L, Shlaes DM, Williamson R, Collatz E. Comparison of vancomycin-inducible proteins from four strains of Enterococci. FEMS Microbiol Lett 1990; 70: $101-106$.

120. Nicas TI, Wu CYE, Hobbs JN, Preston DA, Allen NE. Characterization of vancomycin resistance in Enterococcus faecium and Enterococcus faecalis. Antimicrob Agents Chemother $1989 ; 33: 1121-1124$.

121. Courvalin P. Resistance of enterococci to glycopeptides. Antimicrob Agents Chemother 1990; 34: 2291-2296.

122. Nicas TI, Cole CT, Preston DA, Schabel AA, Nagarajan R. Activity of glycopeptides against vancomycin-resistant gram-positive bacteria. Antimicrob Agents Chemother $1989 ; 33: 1477-1481$.

123. Al-Obeid S, Collatz E, Gutmann L. Mechanism of resistance to vancomycin in Enterococcus faecium D366 and Enterococcus faecalis A256. Antimicrob Agents Chemother 1990; 34: $252-256$

124. Moore EP, Speller DCE. In-vitro teicoplanin-resistance in coagulase-negative staphylococci from patients with endocarditis from a cardiac surgery unit. $J$ Antimicrob Chemother 1988; $21: 417-424$.

125. Wheat PF, Magee JT, Harris DM, Spencer RC. Analysis of bacterial species and antibiotic susceptibility patterns using a microcomputer: an outline of one year's experience. Med Lab Sci 1985; 42: 139-147.

126. Gaunt PN, Phillips I. Computers and hospital infection. $J$ Hosp Infect 1987; 9: 106-109.

127. Phillips I, King A, Gransden WR, Eykyn SJ. The antibiotic sensitivity of bacteria isolated from the blood of patients in St Thomas' Hospital, 1969-1988. J Antimicrob Chemother $1990 ; 25$ Suppl C: $59-80$.

128. Spencer RC, Wheat PF, Harris DM. Microcomputer surveillance as an aid to rational antibiotic therapy for urinary tract infection (UTI) in general practice. Health Trends $1986 ; 4: 84-86$

129. Edwards R, Greenwood D. Antibiotic resistance in enterococc in Nottingham. $J$ Antimicrob Chemother $1990 ; 26: 155$ 156

130. Powell M, Koutsia-Carouzou C, Voutsinas, D, Seymour A Williams JD. Resistance of clinical isolates of Haemophilus influenzae in United Kingdom 1986. Br Med J 1987; 295: $176-179$.

131. Lovering AM, Bywater MJ, Holt HA, Champion HM, Reeves DS. Resistance of bacterial pathogens to four aminoglycosides and six other antibacterials and prevalence of aminoglycoside modifying enzymes, in 20 UK centres. $J$ Antimicrob Chemother 1988; 22:823-839.

132. George RC, Ball LC, Norbury PB. Susceptibility to ciprofloxacin of nosocomial gram-negative bacteria and staphylococci isolated in the UK. J Antimicrob Chemother 1990 26 Suppl F : 145-156.

133. Ward LR, Threlfall EJ, Rowe B. Multiple drug resistance in salmonellae in England and Wales: a comparison between 1981 and 1988. J Clin Pathol 1990; 43: 563-566.

134. Lorian V, Atkinson B. Bacterial resistance to antibiotics in the United States. Ten million strains, nine species and sixteen antibiotics. Drugs Exp Clin Res 1987; 13: 457477

135. Spencer RC, Wheat PF, Magee JT, Brown EH. A three year survey of clinical isolates in the United Kingdom and their antimicrobial susceptibility. $J$ Antimicrob Chemother $1990 ; 26: 435-446$.

136. Magee JT. Microbe Base. London, Academic Press. 1986

137. Williams RJ, Lindridge MA, Said AA, Livermore DM, Williams JD. National survey of antibiotic resistance in Pseudomonas aeruginosa. J Antimicrob Chemother 1984; 14: 9-16.

138. Echeverria $P$, Verhaert L, Ulyangco CV et al. Antimicrobial resistance and enterotoxin production among isolates of Escherichia coli in the Far East. Lancet 1978; 2: 589-592.

139. Wachsmuth IK, Falkow S, Ryder RW. Plasmid-mediated properties of a heat-stable enterotoxin-producing Escherichia coli associated with infantile diarrhea. Infect Immun $1976 ; 14: 403-407$.

140. Smith HW, Linggood MA. Transfer factors in Escherichia col with particular regard to their incidence in enteropathogenic strains. J Gen Microbiol 1970; 62: 287-299.

141. Laporta MZ, Silva MLM, Scaletsky ICA, Trabulsi LR. Plasmids coding for drug resistance and localized adherence to HrLa cells in enteropathogenic Escherichia coli O55:H and O55:H6. Infect Immun 1986; 51 : 715-717.

142. Clausen CR, Christie DL. Chronic diarrhea in infants caused by adherent enteropathogenic Escherichia coli. J Pediatr 1982; 100: 358-361

143. Dorman CJ, Chatfield S, Higgins CF, Hayward C, Dougan G. Characterization of porin and $O m p \mathrm{R}$ mutants of a virulent strain of Salmonella typhimurium: Omp R mutants are attenuated in vivo. Infect Immun 1959; 57: 2136 2140.

144. Curtis R, Kelly SM. Salmonella typhimurium deletion mutants lacking adenylate cyclase and cyclic AMP receptor protein are virulent and immunogenic. Infect Immun 1987; 55: 3035-2043.

145. Bernadini ML, Fontaine A, Sansonetti PJ. The two-component regulatory system ompR-env $Z$ controls the virulence of Shigella flexneri. J Bacteriol 1990; 172: 6274-6281

146. Bryan LE, Godfrey AJ, Schollardt T. Virulence of Pseudomonas aeruginosa strains with mechanisms of microbial persistence for $\beta$-lactam and aminoglycoside antibiotics in a mouse infection model. Can J Microbio $1985 ; 31: 377-380$.

147. Ravizzola G, Pirali F, Paolucci A et al. Reduced virulence in ciprofloxacin-resistant variants of Pseudomonas aeruginosa strains. J Antimicrob Chemother $1987 ; 20: 825-829$

148. Marples RR, Cooke EM. Current Problems with methicillinresistant Staphylococcus aureus. J Hosp Infect 1988; 11 381-392.

149. Cookson BD, Phillips I. Epidemic methicillin-resistant Staphylococcus aureus. J Antimicrob Chemother 1988; 21 Suppl C: $57-65$.

150. Lacey RW, Barr KW, Barr VE. Inglis TJ. Properties of methicillin-resistant Staphylococcus aureus colonizing patients in a burns unit. $J$ Hosp Infect 1986; $7: 137-148$ 
151. Roberts JI, Gaston MA. Protein A and coagulase expression in epidemic and non-epidemic Staphylococcus aureus. $J$ Clin Pathol 1987; 40: 837-840.

152. Jordans JZ, Duckworth GJ, Williams RJ. Production of "virulence factors" by "epidemic" methicillin-resistant Staphylococcus aureus in vitro. J Med Microbiol $1989 ; 30$ 245-252.

153. Baird DR, Lennie S, Gemmell CG. Comparison of the susceptibility of methicillin-sensitive (MS) and methicillin-resistant (MR) Staphylococcus aureus to opsonophag- ocytosis. Abstract no 164, 6th International Symposium on Infections and the Immunocompromised Host 1990.

154. Piddock LJV, Wise $R$. Induction of the SOS response in Escherichia coli by 4-quinolone antimicrobial agents. FEMS Microbiol Lett 1987; 41 : 289-294.

155. Limb DI, Dabbs DJW, Spencer RC. In-vitro selection of bacteria resistant to the 4-quinolone agents. $J$ Antimicrob Chemother 1987; 19: 65-71.

156. Gemmell CG, Felmingham D. New techniques for assessing pathogenicity of quinolone-resistant bacteria. $J$ Antimicrob Chemother 1990; 26 Suppl F : 157-163. 